\title{
Os "pequenos" conjuntos Cecap derivados de Guarulhos e Jundiaí: uma análise comparativa
}

\author{
The "small" housing complex Cecap derivatives from
}

Guarulhos and Jundiai: a comparative analysis

\section{Wilton Flávio Camoleze Augusto Sidnei Junior Guadanhim}

\section{Resumo}

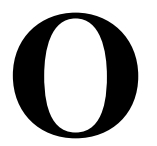

Conjunto Habitacional Zezinho Magalhães Prado, em Guarulhos, SP, projetado por Vilanova Artigas, Fábio Penteado e Paulo Mendes da Rocha, desempenha papel de projeto seminal. Como no interior do estado foram desenvolvidos conjuntos que seguiram os conceitos aplicados em Guarulhos, a pesquisa buscou verificar em que medida aconteceram as reproduções nos conjuntos de Jundiaí, Marília e Mogi-Guaçu, estes em menor escala e em diferentes contextos. Também buscou verificar o aprimoramento das soluções projetuais. Por meio das visitas, da análise dos projetos e das informações reunidas, foi possível identificar elementos nos projetos e construídos de fato, que foram graficamente representados e reunidos em quadros comparativos. A análise comparativa buscou verificar a relação entre os projetos e a construção dos conjuntos habitacionais. A semelhança entre os conjuntos de Jundiaí, Marília e Mogi-Guaçu reforça a hipótese de utilização de um modelo com adequação ao lugar de implantação. O registro "dos pequenos" conjuntos Cecap de Marília e Mogi-Guaçu contribui para a disseminação deste importante momento da arquitetura brasileira.

Palavras-chaves: Arquitetura moderna. Cecap. Conjuntos Habitacionais Cecap. Habitação social. Conjunto Habitacional Zezinho Magalhães Prado. Jundiaí. Marília. Mogi-Guaçu.

Wilton Flávio Camoleze Augusto Universidade de Marília Marília - SP - Brasil

Sidnei Junior Guadanhim Universidade Estadual de Londrina Londrina - PR - Brasil

Recebido em 04/04/15 Aceito em 25/03/16

\begin{abstract}
The Housing Complex Zezinho Magalhães Prado in Guarulhos, SP, designed by Vilanova Artigas, Fábio Penteado and Paulo Mendes da Rocha, plays a seminal role project. Because of the sets development in the countryside, that followed the concepts applied in Guarulhos, the report verified to what extent have happened reproductions in sets of Jundiai, Marã Lia and Mogi-Guaçu, these on a smaller scale and in different contexts. The research also tried to verify the constant improvement of design solutions. Through the visits, the analysis of projects and information gathered, it was possible to identify elements in projects and constructed fact, which were graphically represented and gathered in comparative tables. The comparative analysis aimed to investigate the relationship between the projects and the construction of housing. The adoption of ramps in vertical movement, the group of buildings and the scale reduction of housing are examples of design solutions that aimed to actual construction. The similarity between the sets of Jundiai, Marilia and Mogi-Guaçu reinforces the hypothesis of use of a model adequacy to place of deployment The detailed datas of "small" Cecap Marilia and Mogi-Guaçu contributes to the dissemination of this importante period of the Brazilian architecture.
\end{abstract}

Keywords: Modern architecture. Cecap. Cecap Housing Complex. Social Housing. Zezinho Magalhães Prado Housing Complex. Jundiaí. Marília. Mogi-Guaçu. 


\section{Introdução}

A Caixa Estadual de Casas para o Povo (Cecap), criada em 1949 para desenvolver programas habitacionais no estado de São Paulo, decidiu implantar em 1966 um grande conjunto habitacional na cidade de Guarulhos, com financiamento do Banco Nacional da Habitação (BNH), criado dois anos antes. O projeto ficou a cargo dos arquitetos Vilanova Artigas e Fábio Penteado e, posteriormente, Paulo Mendes da Rocha. Denominado Conjunto Habitacional Zezinho Magalhães do Prado, homenagem ao então superintendente da Cecap, tornou-se de certa forma um modelo que influenciaria a produção de habitações sociais em larga escala no Brasil.

O projeto revela a incorporação de ideais da arquitetura moderna compartilhados pela equipe de arquitetos. Por suas características, o conjunto figura como um dos ícones da Arquitetura Moderna no Brasil (CUNHA, 2009; CERÁVOLO, 2007). O programa é complexo, diferente de outras realizações de companhias públicas de habitação (ZANDONADE, 2005). O contexto, o projeto e a obra, assim como as ações do BNH, são fartamente documentados e discutidos na literatura ${ }^{1}$; Nos diversos trabalhos, o conjunto é abordado sob vários pontos de vista - como projeto urbano, como resposta ao cenário brasileiro da época, pósgolpe militar, como experiência com industrialização da construção e como postura diante das discussões sobre a cidade pós-moderna (MEDRANO; RECAMÁN, 2013).

Fábio Penteado, em entrevista a Gabriel Cunha, comenta que foram feitas visitas a várias cidades do Estado de São Paulo com a finalidade de buscar apoio das prefeituras para a implantação de novos conjuntos habitacionais, procurando seguir e desenvolver as experiências do conjunto Cecap Guarulhos, e recordou-se especificamente dos casos de Americana e Jundiaí.

Em 1972 foram realizados estudos preliminares para o conjunto de Americana, que acabou não sendo executado, ao que tudo indica, por divergências e falta de apoio local. O conjunto habitacional da Cecap em Jundiaí, projetado em 1973, foi executado, graças ao envolvimento da prefeitura (CUNHA, 2009). Além desses casos, foram construídos pelo menos mais dois conjuntos no interior do Estado: Marília, projetado em 1976, e Mogi-Guaçu, projetado em 1977, os menores e menos conhecidos conjuntos derivados de Guarulhos. Um aspecto importante a destacar é que tais propostas foram desenvolvidas durante a

${ }^{1}$ Uma detalhada descrição e análise do conjunto Zezinho Magalhães é feita por Ruth V. Zein (2005). construção do conjunto em Guarulhos, cujas obras, pela própria magnitude, pioneirismo e custo do empreendimento, estenderam-se de 1973 a 1981 , em três etapas com alterações em relação ao projeto original (CERÁVOLO, 2007). É lógico supor que os projetos subsequentes possivelmente incorporaram o aprendizado.

Os projetos de Americana - apesar de não executado - e de Jundiaí são frequentemente citados na literatura. O caso de Marília, entretanto, mencionado por Arantes (2002) e Cunha (2009), tem menos repercussão e destaque. $\mathrm{O}$ projeto de Mogi-Guaçu não é abordado pelos autores que trataram do tema, ficando fora do recorte temporal do trabalho de Cunha ${ }^{2}$. Assim, o registro detalhado e a disseminação dos casos de Marília e MogiGuaçu são de especial interesse. Sua comparação com os conjuntos anteriores e a verificação de como as diferentes soluções projetuais e construtivas das três etapas de construção em Guarulhos foram reaplicadas, pretendem contribuir para o registro e a compreensão desse importante episódio da produção de habitação de interesse social no Brasil.

Toda abordagem sobre os conjuntos Cecap inevitavelmente se depara com um grande leque de possibilidades de discussão. Os estudos mais recentes sobre a obra de Artigas têm lançado luz e revisitado algumas versões consensuais de sua obra. Por exemplo, Medrano e Recamán (2014) ao estudar a obra residencial do arquiteto das décadas de 1940 a 1960 apontam contradições entre a arquitetura moderna e a conformação das cidades (CAMARGO, 2014). Tratando especificamente do conjunto de Zezinho Magalhães os autores consideram o espaço coletivo como resíduo da multiplicação dos blocos, todos idênticos, com freguesias idênticas, resultando em grande homogeneidade - um anacronismo oriundo da modernidade arquitetônica de décadas passadas que influenciaria negativamente a produção de habitações sociais no Brasil, com inevitáveis consequências do ponto de vista social (MEDRANO; RECAMÁN, 2013).

O conjunto Cecap de Guarulhos teve um papel importante na afirmação do modelo de habitação que seria adotado nos anos seguintes. Vilanova Artigas e Mendes da Rocha tinham grande

${ }^{2}$ Arantes (2002) menciona ainda projetos não executados para a Cecap em Cubatão (1970) e Jaú (1976). Na relação de obras de Artigas constantes no arquivo de originais da FAUUSP, não consta o projeto de Cubatão. (KATINSKY, 2005). Guarulhos, Americana, Jundiaí, Marília e Jaú são abordados por Cunha (2009), que, não obstante afirma que Mogi-Guaçu não fora executado (p. 189). Para Jaú o projeto não era derivado de Guarulhos; foram projetadas casas unifamiliares. 
representatividade entre os arquitetos e a ampla divulgação desse projeto reforçou tal opção como "modelo ideal" de habitação social a ser provido pelo Estado. Além disso, principalmente nos grandes centros, os técnicos que atuavam nas companhias de habitação tinham uma formação com a mesma orientação, “[...] herança dos modelos consagrados dos IAPs, das realizações europeias pós-guerra e da repercussão positiva das super-quadras de Brasília [...]" (ZANDONADE, 2005, p. 126).

Embora não alheio a essas questões, o presente trabalho tem um recorte restrito. O objetivo é, além de registrar e disseminar os "pequenos" conjuntos Cecap, verificar quais mudanças e transformações ocorreram nos seus projetos e examinar as possíveis razões. Para alcançá-lo, pretende-se, de modo específico, identificar os elementos propostos em projeto que foram executados e quais as diferenças entre a proposta e a execução dos conjuntos; identificar as variações projetuais e construtivas na implantação dos conjuntos construídos em seus diferentes contextos e verificar em que medida as reproduções dos projetos aconteceram em cada cidade.

\section{Método}

Segundo Yin (2010), questões do tipo "como" ou "porque" são exploratórias e levam ao uso dos estudos de caso, pesquisas históricas e experimentos como métodos de pesquisa, tendo como distinção entre si a extensão do controle e do acesso do investigador sobre os eventos comportamentais reais. $\mathrm{O}$ autor também relata que a utilização das pesquisas históricas é preferivelmente adotada quando realmente não existe acesso ou controle.

A pesquisa que gerou este trabalho partiu da seguinte hipótese: o conjunto Cecap Guarulhos atuou como projeto seminal. Por meio dele foram realizadas experiências posteriores em menor escala e em contextos diferentes - estudos para Americana e a construção em Jundiaí, Marília e Mogi-Guaçu. Apesar de derivados, tais conjuntos não aparentam ser somente uma reprodução literal do projeto original.

Considerando o Conjunto Habitacional Cecap Zezinho Magalhães Prado em Guarulhos um modelo a ser reproduzido, em que medida as reproduções aconteceram e quais as mudanças a partir do modelo original? Os "pequenos" conjuntos Cecap possuem adaptações que não os fazem ser uma mera cópia?

A metodologia utilizada neste trabalho contou com técnicas da pesquisa histórica ao analisar documentos e fatos do passado. Também foi desenvolvida uma análise comparativa dos conjuntos de Guarulhos, Jundiaí, Marília e MogiGuaçu. Os itens verificados na análise comparativa foram representados graficamente e reunidos em quadros comparativos dos conjuntos. Embora o conjunto de Americana não tenha sido incluído na comparação, por não ter sido executado, o projeto merece menção, primeiramente devido à documentação existente e, principalmente, por haver claros indícios de reaplicação das soluções nos conjuntos posteriores.

\section{Conjunto habitacional Zezinho Magalhães Prado: considerações necessárias}

O projeto do Conjunto Habitacional Zezinho Magalhães Prado foi a primeira experiência da Cecap em projetos de grande porte, sendo coordenado pelos arquitetos João Batista Vilanova Artigas, Fábio Penteado e Paulo Mendes da Rocha $^{3}$, expoentes da linha paulista de arquitetura moderna. O projeto iniciou-se em 1967, a construção teve sua primeira fase iniciada em 1973 e prosseguiu até 1981 (CERÁVOLO, 2007; SEGAWA, 2002; ZEIN, 2005).

$\mathrm{O}$ conjunto fora planejado para 50 mil habitantes numa área de $1.800 .000 \mathrm{~m}^{2}$, com previsão de construção de 10.560 apartamentos. Do ponto de vista urbanístico, o espaço fora organizado seguindo o conceito de freguesia ${ }^{4}$. Cada freguesia era composta de agrupamentos de edifícios e equipamentos urbanos que possuíam um centro comercial e uma escola, e composta de quatro grupos de edifícios, englobando oito blocos das unidades habitacionais (FERRAZ, 1997; SEGAWA, 2002; ZEIN, 2005).

Zein (2005) destaca que a experiência do projeto do conjunto Cecap Guarulhos contribuiu para reforçar paradigmas que vinham se estabelecendo há algum tempo como:

\footnotetext{
${ }^{3} \mathrm{O}$ projeto do conjunto Cecap Zezinho Magalhães Prado também teve a participação dos arquitetos colaboradores Arnaldo Martino, Geraldo Vespasiano Puntoni, Maria Giselda C. Visconti, Renato Nunes e Ruy Gama.

${ }^{4}$ Termo tradicional do urbanismo português que relaciona a comunidade com vínculos eclesiásticos. No projeto do conjunto Cecap Zezinho Magalhães Prado, o termo fora atualizado para um conjunto de pessoas com interesses comunitários (SEGAWA, 2010).
} 


\begin{abstract}
[...] a multidisciplinaridade da equipe de projeto, o desejo de aproveitamento máximo das possibilidades tecnológicas da construção e finalmente, mas não menos importante, a valorização dos serviços $e$ equipamentos urbanos; bem como exercitar a aplicação da ideia da possibilidade de repetição da unidade habitacional enquanto fator básico para se buscar atingir uma economia de escala (ZEIN, 2005, p. 209).
\end{abstract}

No projeto do conjunto Cecap Guarulhos foi adotada a repetição de uma unidade tipo. O agrupamento de unidades formam os edifícios habitacionais laminares com quatro pavimentos (térreo, mais três pavimentos) justapostos em pares numa malha ortogonal. São servidos por caixas de escadas que ligam os edifícios em pares, transformando-os em um único bloco com pátios internos. A dispensa dos corredores internos aos apartamentos através da disposição das caixas de escadas permitiu aos apartamentos possuírem aberturas para as duas faces do edifício, favorecendo iluminação e ventilação (CUNHA, 2009; KAMITA, 2000; ZEIN, 2005).

A Figura 1 ilustra a implantação geral, conforme a proposta inicial para o Conjunto Habitacional Zezinho Magalhães Prado, porém durante as três etapas de projeto e construção pelas quais passou o conjunto, sua implantação não se deu na totalidade. Foram executados os condomínios, conforme destacado na Figura 2, em que é possível verificar a vista geral do conjunto Cecap Guarulhos atualmente, totalizando 4.680 unidades habitacionais (CERÁVOLO, 2007).

O conjunto foi concebido originalmente visando a industrialização ${ }^{5}$ da construção. Paulo Mendes da Rocha afirmou que " [...] o projeto foi então visto de forma a ser executado dentro de uma técnica de concreto armado com perspectiva de aproximação à pré-fabricação e da pré-moldagem [...]"
(REVISTA DESENHO, 1972). Fábio Penteado relata em depoimento a Fabiana Cerávolo (2007) que o projeto inicial foi concebido de modo que os edifícios fossem totalmente pré-fabricados, tendo sido, inclusive, contratado e desenvolvido todo o projeto estrutural de pré-moldados, que "custou uma fortuna" (p. 88). A perspectiva "da montagem dos elementos pré-moldados dos blocos de habitação" publicada em Acrópole (ACRÓPOLE, 1970) evidencia a estratégia proposta da produção em série de componentes de concreto que permitiriam a montagem também seriada dos edifícios.

A equipe de arquitetos, imbuída dos ideais modernistas, desde as primeiras ideias vislumbrava a introdução de processos industriais na construção, algo que ocorria de modo extensivo na Europa, principalmente nos esforços de reconstrução das cidades no pós-Segunda Guerra Mundial. As principais decisões de projeto foram tomadas sob essa perspectiva, incluindo a préfabricação e até mesmo o projeto de equipamentos e eletrodomésticos.

O espírito remetia aos conceitos modernos dos CIAMs e consoantes à prática corrente nos países europeus na reconstrução pós-Segunda Guerra Mundial. O momento nacional era marcado pelo debate sobre como poderia ocorrer o desenvolvimento do país e particularmente da industrialização da construção. Paulo Mendes da Rocha, ao explicar na época o projeto, expõe tal preocupação com a pré-fabricação e prémoldagem, visando não apenas rapidez e economia de escala, mas qualidade construtiva e habitabilidade. Utilizando o termo "economia social", destaca a importância da racionalidade para viabilizar boas unidades dentro das condições de restrição financeira, promovendo melhorias sociais (REVISTA DESENHO, 1972).

\footnotetext{
${ }^{5}$ Blachére (1978) conceitua, em termos gerais, industrialização como o resultado da soma entre racionalização e mecanização. Para o autor, "a industrialização é a utilização de tecnologias que substituem a habilidade do artesão pelo uso da máquina" ( $p$ 9). Bruna (2002) ressalta a industrialização como uma estratégia em que a produção em série, pautada pela padronização dos elementos, pede a mecanização dos meios de produção para que seja possível atender a uma alta demanda aliada à economia de recursos. Já a pré-fabricação na construção civil é a “fabricação dos componentes antes da execução, no próprio canteiro ou fora, e que em uma fábrica a habilidade do artesão é substituída pelo uso da máquina" (MONTENEGRO FILHO, 2007, p. 15). A implementação de processos industriais na construção civil é decorrência de uma preocupação com a racionalização construtiva, ou seja, um processo composto pelo conjunto de ações para otimizar todos os recursos disponíveis - materiais, humanos, organizacionais, energéticos, tecnológicos, temporais e financeiros - em todas as fases da construção. (SABATTINI, 1989).
} 
Figura 1 - Conjunto Zezinho Magalhães Prado em Guarulhos, SP, 1967 - implantação geral

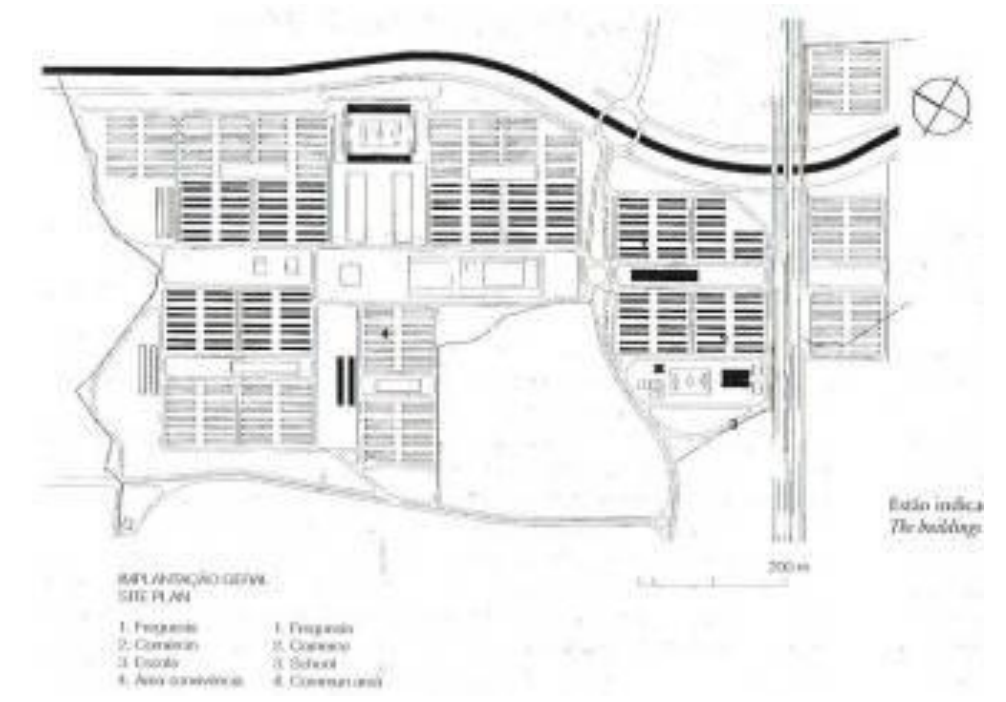

Fonte: Ferraz (1997, p. 143).

Figura 2 - Conjunto Zezinho Magalhães Prado em Guarulhos, SP, 2013 - vista geral com localização dos condomínios e indicação das respectivas etapas de construção

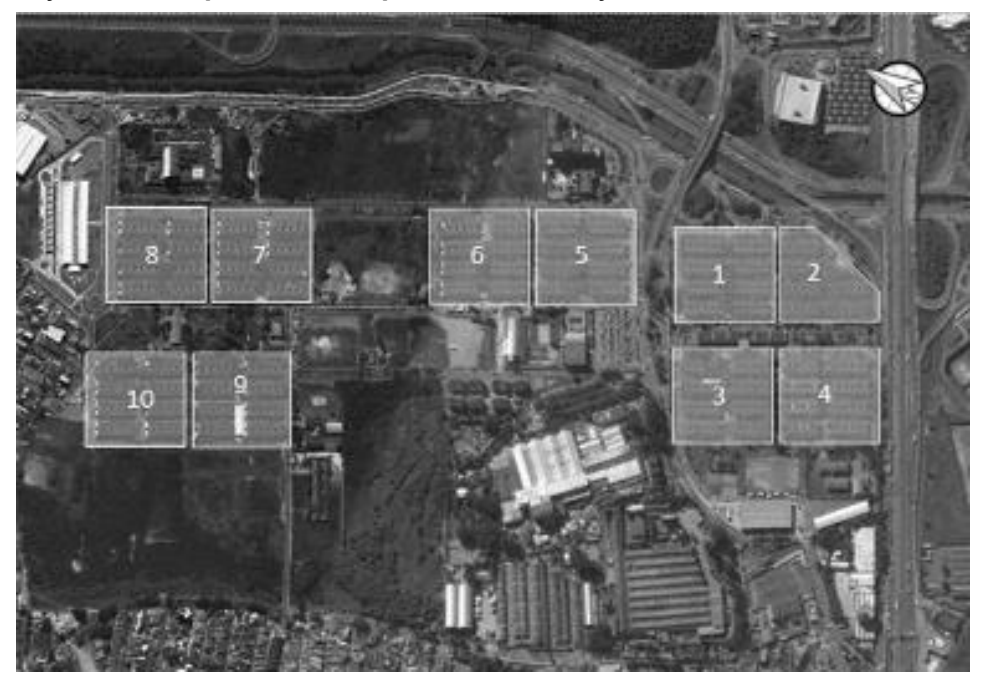

Fonte: Google Earth, adaptado pelos autores.

Nota: Legenda:

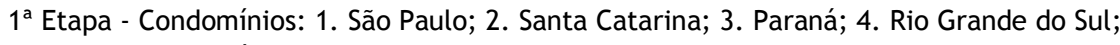

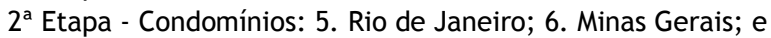

$3^{\text {a }}$ Etapa - Condomínios: 7. Espírito Santo; 8. Bahia; 9. Alagoas; 10. Sergipe.

A conjuntura inviabilizava, entretanto, a préfabricação. A obra foi executada de modo tradicional, exceto pelas escadas e por alguns componentes na segunda e terceira etapas. Se por um lado a indústria da construção civil não estava preparada para tal tarefa e a instalação de uma usina exclusiva para a realização daquela obra era economicamente impossível, a exploração corrente da mão de obra não especializada e barata, estimulada até pelo próprio $\mathrm{BNH}$, também era um fator inibidor (SEGAWA, 2010; CUNHA, 2009; MEDRANO; RECAMÁN, 2013). Isso foi, inclusive, mencionado textualmente por Penteado ao responder por que não foi utilizada a préfabricação desde a primeira fase, em entrevista concedida em 1970:

Existe uma bicondição na política do $\mathrm{BNH}$ que é contrária a este processo. É que na verdade o país tem a necessidade anual de dois milhões de empregos, portanto, se adotada a política de industrialização pensam eles que se tiraria a condições de tantos mil trabalhadores (REVISTA DESENHO, n. 4). 
Zein (2005), por sua vez, enfatiza a primeira razão, recusando-se a creditar apenas "à incúria política e econômica" a inviabilidade da pré-fabricação naquele caso, uma vez que desde Le Corbusier a pré-fabricação para a produção de habitações em série - apesar de lógica e inevitável na retórica modernista - é de fato um desafio colossal na construção civil. No período de seu estudo, aparentemente a única experiência de sucesso na produção de habitações empregando préfabricação efetivamente realizada foi o Conjunto Residencial da USP (CRUSP).

De fato, a pré-fabricação foi "seu tema e não sua realidade" e a homogeneidade consequente - de unidades, de edifícios, de espaços livres constitui-se um ponto crítico da proposta (MEDRANO; RECAMÁN, 2013, p. 126). Além disso, o conjunto foi implantado sem uma inserção cuidadosa na estrutura urbana - ainda que escassa - existente no entorno. "Seu traçado assumiu uma lógica interna, desassociada do entorno, marcando sua unidade urbana independente das estruturas pré-existentes [...]" (ZANDONADE, 2005, p. 118).

Porém, é preciso considerá-la como resultado da equação que privilegiou a racionalidade. $\mathrm{O}$ modelo adotado remetia diretamente aos postulados defendidos por Gropius em 1930 no $3^{\circ}$ CIAM, com base nos quais propunha blocos lineares $\mathrm{e}$ paralelos que visavam garantir vistas, ventilação e insolação adequadas de modo equitativo a todas as unidades (GROPIUS, 1977). Pode-se afirmar que não obstante a preocupação dos arquitetos em aproximar o discurso de uma arquitetura local - ao adotar o termo freguesia, por exemplo - o conjunto de Guarulhos deriva das experiências europeias das décadas de 1920 e 1930, nas quais o problema da habitação passava a ser tratado de modo científico, com caráter racional e objetivo (BRUNA, 2002).

A crítica a esse modelo modernista de habitação e cidade é largamente conhecida e estudada de modo abrangente desde a década de $1960^{6}$, começando por Venturi. Um dos episódios mais emblemáticos apontados como indício do fracasso do modelo foi a demolição de Pruitt-Igoe em 1972. Os reflexos são vistos até hoje, na medida em que as preocupações com o "[...] uso social, isto é, projetos que podem incluir diferentes padrões de ocupação e mudar com o passar do tempo [...]", estão no centro das discussões sobre habitação urbana (FRENCH, 2009 p. 13). Particularmente na Europa Ocidental notam-se experimentações formais, espaciais e tipológicas visando valores

${ }^{6} \mathrm{~A}$ esse respeito, ver NESBITT (2006). imateriais, por meio de espaços urbanos ricos e diversificados (GUADANHIM, 2014).

Paradoxalmente, o Conjunto Cecap Zezinho Magalhães em termos qualitativos ainda é muito superior ao que se produziu sob a égide do $\mathrm{BNH}$. Ao estudar os conjuntos habitacionais na região Leste da Grande São Paulo, Zandonade (2005) identificou características superiores do Conjunto Zezinho Magalhães quando comparado com os demais conjuntos implantados a partir de 1964: transição mais gradual da esfera pública para a privada, graças à implantação das áreas livres e destinadas a uso comum, apresentando uma escala mais condizente com o entorno; criação efetiva de espaços coletivos, praticamente inexistentes em outros conjuntos; a proposição de equipamentos e comércio local, escolas, igreja, etc. era um passo além de simplesmente atender à demanda de alojamento; dos casos estudados, é o que melhor conserva as características originais - uma indicação de funcionalidade - como a preservação das áreas livres cobertas (pilotis) e descobertas; a vegetação e a arborização estão em bom estado; e as áreas comuns encontram-se bem conservadas. A autora faz a ressalva de que, gradativamente, a população de mais baixa renda à qual o empreendimento se destinava, deu lugar a moradores de camadas de renda mais altas ${ }^{7}$, fato ao qual é atribuída a maior conservação; porém, o inverso pode ser verdadeiro: a melhor qualidade ambiental e a facilidade de acesso teria atraído tais moradores?

Nos discursos dos arquitetos, ao defender a opção pela elevação dos edifícios sobre pilotis, há claras referências aos postulados da Carta de Atenas, como garantir áreas livres, permeabilidade, ventilação e insolação das unidades, espaços para recreação, etc., criando um novo solo útil. Por exemplo, no debate conduzido na FAUUSP em 1968, Mendes da Rocha afirmou que a solução sobre pilotis era uma

[...] decorrência natural do fato de utilizar as áreas ligadas aos planos de acesso para uma série de eventuais atividades muito difíceis de se prever. [...] Áreas ligadas à recreação e que conduzem naturalmente às áreas de comércio [...] aos pontos de ônibus e estacionamentos (REVISTA DESENHO, n. 4).

\footnotetext{
${ }^{7}$ Vilanova Artigas, no debate sobre o conjunto na FAUUSP em 1968, já previa, de certa forma, que a dotação de comércio e equipamentos, bem como as condições de vida proporcionadas pelo espaço valorizariam os imóveis, que poderiam acabar sendo vendidos "para elementos da pequena burguesia" dentro de
} cinco anos. (Revista Desenho, n.4, 1972). 
Artigas, na mesma ocasião, dizia que o verde espaço entre os edifícios e contíguos aos pilotis era um "[...] pano de fundo onde se distribuem as atividades humanas [...]" (REVISTA DESENHO, n. 4). Sylvia Ficher, na época estagiária da Cecap, explica que o uso de pilotis naquele caso, além de adequado ao tipo de solo turfoso da região, liberava "a camada superficial do solo para a circulação dos pedestres e recreação infantil" (FICHER, 1972 apud CERÁVOLO, 2007). Além disso, a economia da solução era obtida também pelo fato de que a amarração da estrutura era feita sem baldrame, mas apenas pela superestrutura.

Fica claro que a ideia inicial era de que tal espaço não fosse ocupado pelos automóveis; na ocasião a demanda por veículos deveria ser pequena, afinal, conforme Fábio Penteado:

[...] quem iria imaginar que o operário lá ia ter automóvel [...], O pilotis é charme, poderia ter deixado pilotis que foi uma invenção, uma discussão do Corbusier interessantíssima, [...] posso dizer que ninguém pensou em automóvel na época, imagina o cara ganhava um salário mínimo na época, quem ia ter carro? [...] Hoje lá cada um tem dois, ainda deve alugar do vizinho (CERÁVOLO, 2007, p. 162) ${ }^{8}$.

Era mais para ganho de terreno. Aquela teoria de você liberar o terreno, de ver através do prédio e ver a paisagem do outro lado [...] (CUNHA, 2009, p. 198) ${ }^{9}$.

Geraldo Vespasiano Puntoni em entrevista à mesma autora também confirma isso: "no começo eram só pilotis, ninguém previu estacionar carros" 10 . Entretanto, ao longo do tempo foi inevitável: o espaço do pilotis se transformou em estacionamento. Atualmente os pavimentos térreos liberados pelos pilotis encontram-se destinados ao uso de estacionamentos em todos os conjuntos (CUNHA, 2009; ZEIN, 2005).

De fato, ao analisar os projetos, verifica-se que há uma continuidade da pavimentação externa destinada à circulação de veículos e ao estacionamento descoberto aos pilotis. Isso certamente facilitou tal apropriação. Embora não haja dados que permitam afirmar de modo conclusivo que isso já estava previsto nos últimos projetos, o desenho induz ao uso do pilotis pelo automóvel. Na planta de Guarulhos de 1978 inclusive consta no selo o título "Térreo- Nível de

${ }^{8}$ Depoimento de Fábio Penteado a Fabiana Cerávolo em $9 / 3 / 2007$.

${ }^{9}$ Depoimento de Fábio Penteado a Gabriel Rodrigues da Cunha em $10 / 12 / 2008$.

${ }^{10}$ Depoimento de Geraldo Vespasiano Puntoni a Fabiana Cerávolo em $17 / 7 / 2007$. estacionamento" e praticamente não há áreas externas destinadas (Figura 3).

\section{Conjuntos derivados de Guarulhos}

\section{Cecap Americana, SP}

Os projetos elaborados para o interior do Estado de São Paulo, a partir de 1972, naturalmente foram feitos em menor escala, em comparação a Guarulhos, ainda que aplicando as experiências obtidas com o conjunto Cecap Guarulhos. Conforme Artigas, "[...] o presente estudo [...] é continuação dos [...] que vimos fazendo. Trata-se do aproveitamento de uma nova área, oferecida pela prefeitura municipal [...]" (FERRAZ, 1997, p. 174).

O estudo para o conjunto habitacional de Americana, de 1972 (Figuras 4 e 5), contemplava uma população de aproximadamente dois mil moradores. Trata-se de uma proposta mista, com sobrados em renque e edifícios de apartamentos.

$O$ prefeito de Americana, o governo, foi radicalmente contra no começo [...] Lembro-me que eu fiz, que eи coloquei, na Câmara Municipal, a importância de ter a formação de uma cidade ao lado de uma 'água bonita', e colocar junto da habitação o lazer próximo, que era uma tese mundialmente conhecida e desenvolvida na época [...] (CUNHA, 2009, p. 86) ${ }^{11}$.

$\mathrm{O}$ conjunto habitacional de Americana acabou não sendo construído. Conforme Penteado sua execução não foi efetivada por desentendimento e falta de apoio do governo municipal.

O conjunto Cecap em Americana é descrito e apresentado nesta seção, porém não integra a posterior análise comparativa. Por não ter sido executado, não é possível tratá-lo em nível de igualdade perante os demais conjuntos, visto que a análise comparativa tratará de elementos que foram propostos em projeto e efetivamente executados nos conjuntos. Porém, há claros indícios de que o conjunto Cecap Americana contribuiu para o desenvolvimento dos conjuntos analisados.

\footnotetext{
${ }^{11}$ Depoimento de Fábio Penteado a Gabriel Rodrigues da Cunha em $10 / 12 / 2008$. Nesse depoimento inclusive menciona que ele Artigas participaram do processo de contatar as prefeituras, recordando-se, especificamente de Americana e Jundiaí (CUNHA, 2009).
} 
Figura 3 - Implantação Guarulhos, 1978

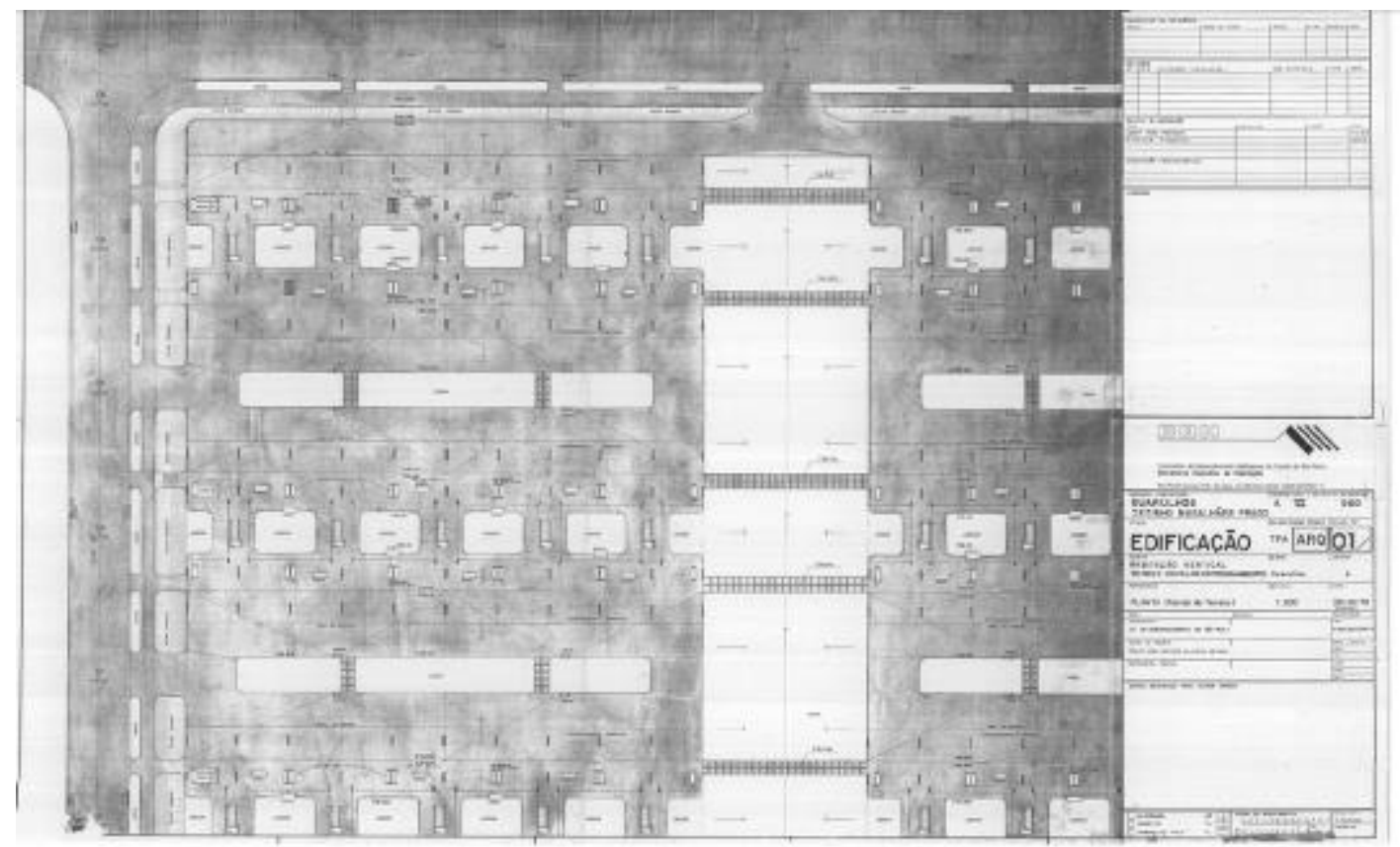

Fonte: Arquivo FAU-USP (sem data).

Figura 4 - Conjunto Cecap Americana, SP, 1972 - estudo preliminar - implantação

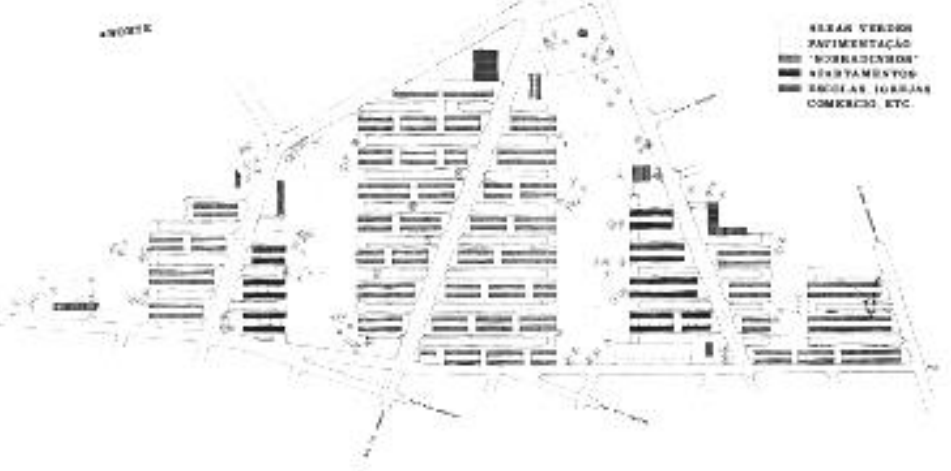

Fonte: Arquivo FAU-USP (sem data).

Figura 5 - Conjunto Cecap Americana, SP, 1972 - estudo preliminar - planta pavimento tipo

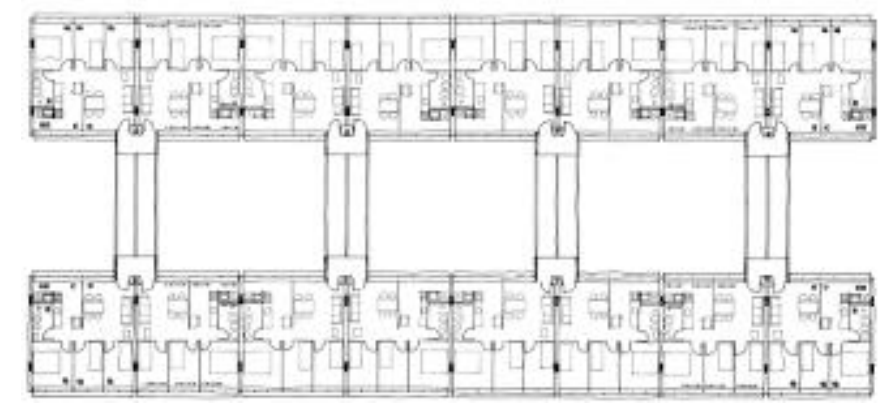

Fonte: Arquivo FAU-USP (sem data). 
Em Americana foram propostas rampas para a circulação vertical, o que difere completamente da circulação vertical adotada nas três etapas de execução em Guarulhos. Nesse caso, os blocos laminares são implantados a meios níveis, unidos pelas rampas, adequando-se ao relevo. Essa solução seria adotada nos conjuntos posteriores.

Artigas já trabalhava com meios níveis em suas obras. Alguns exemplos precedentes da utilização dessa solução são a Casa Heitor Almeida (1949), a Estação Rodoviária e a Casa da Criança de Londrina (1950), a Faculdade de Arquitetura e Urbanismo da Universidade de São Paulo (1961) e a Casa Martirani (1969).

\section{Conjunto Cecap Jundiaí, SP}

O conjunto Cecap Jundiaí foi projetado em 1973 e previa a construção mais de 2.000 unidades, porém foram construídas 432 . Os blocos são similares aos de Guarulhos e Americana com apartamentos de aproximadamente $64 \mathrm{~m}^{2}$. Em Jundiaí a proposta inicial para a implantação dos 32 blocos previa equipamentos coletivos de lazer a todo o conjunto, como campos de futebol e quadras poliesportivas. Foram realizados somente seis blocos (Figuras 6 e 7), que também se encontram atualmente em delimitação e fechamento em sistema de condomínios.

Esse conjunto difere do de Guarulhos ao adotar as rampas e os meios níveis, idênticos aos do projeto de Americana. Difere do de Guarulhos e Americana na organização da implantação, resolvida não em conjuntos de blocos paralelos de mesma extensão, mas com comprimentos diferentes, alternando o lado das circulações, formando subconjuntos com seis blocos. Assim, como nas últimas etapas de Guarulhos, o desenho dos pavimentos externos facilita a apropriação dos pilotis por automóveis.

\section{Os "pequenos" conjuntos Cecap: Marília e Mogi-Guaçu, SP}

O conjunto Cecap Maria Izabel, na cidade de Marília, SP, foi executado entre os anos de 1976 a 1978. Repete o partido básico de Jundiaí, tanto em termos de conformação dos blocos como quanto à circulação vertical por rampas. Porém, em Marília, trata-se de uma implantação em menor escala, não chegando a constituir-se uma proposta urbanística, pois não contemplava a ideia de freguesia nem possuía equipamentos e área comercial, mas ocupava um terreno bem menor em comparação aos conjuntos anteriores.

Figura 6 - Conjunto Cecap Jundiaí, SP, 2013 - vista geral

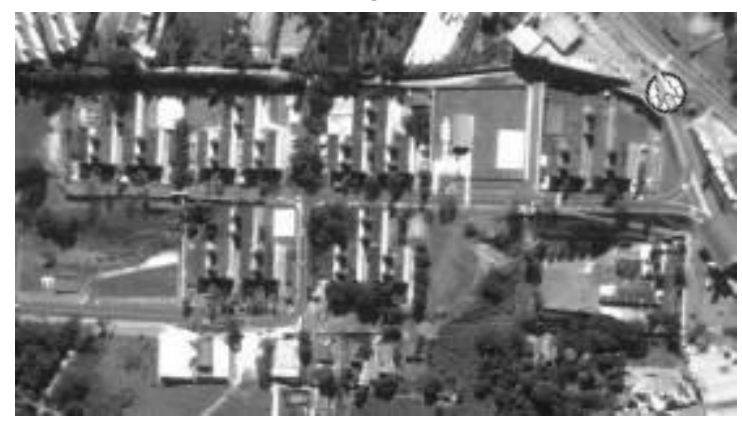

Fonte: Google Earth.

Figura 7 - Conjunto Cecap Jundiaí, SP, 1973 - implantação

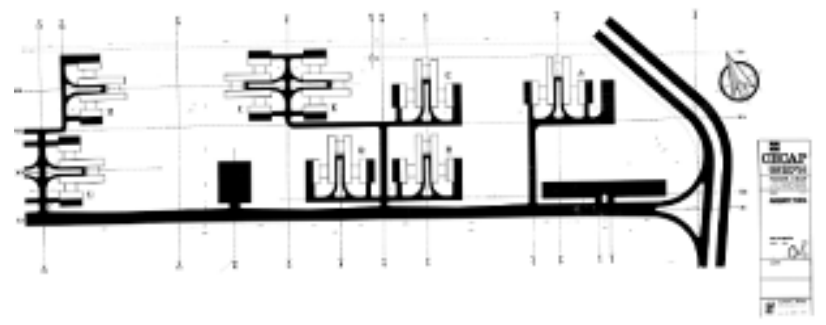

Fonte: Arquivo FAU-USP (sem data). 
A solução adotada é composta de apenas dois subconjuntos de seis edifícios cada um (Figuras 8 e 9), totalizando 144 apartamentos. Diferentemente dos demais, em Marília o conjunto habitacional ainda mantém a característica original, com fechamento realizado por alambrado e cerca viva, sem portões que limitam o acesso, tampouco portarias ou guaritas como nos demais conjuntos. Há somente a barreira física indicando a delimitação da área do conjunto, que também se encontra constituído em sistema de condomínio.

O conjunto Cecap Mogi-Guaçu é o menor conjunto derivado do projeto original de Guarulhos. Com apenas 72 unidades, é composto de um subconjunto de seis edifícios, exatamente a metade de Marília (Figuras 10 e 11). Igualmente se trata de uma implantação pontual em um terreno de dimensões reduzidas, $8.238,88 \mathrm{~m}^{2}$, sem nenhuma pretensão maior em termos urbanísticos. Desenhado em 1977, basicamente o projeto é idêntico ao anterior. A aplicação das rampas é adequada ao relevo, que se apresenta em leve declive, o que permite a acomodação do conjunto de modo natural.

Um exame dos projetos de pavimentação exterior e estacionamentos leva à mesma conclusão quanto ao uso dos pilotis: a contiguidade dos acessos e da pavimentação externa ao espaço sob os blocos indica que, naquele momento, já se assumia o uso dos pilotis como estacionamento; os carros são desenhados nos pilotis, no estudo de Jundiaí (Figura 12).

Figura 8 - Implantação do conjunto Cecap Maria Izabel - 2013 - Marília, SP

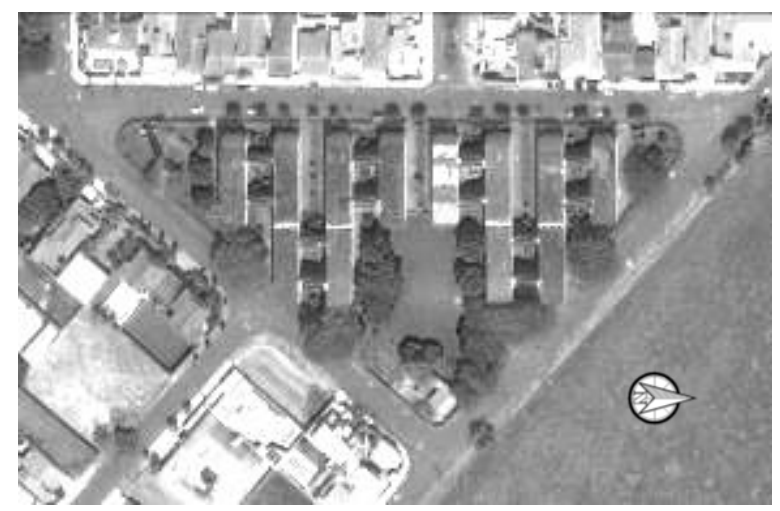

Fonte: Google Earth, adaptado pelos autores.

Figura 9 - Conjunto Cecap Maria Izabel, Marília, SP - croqui implantação/fachada

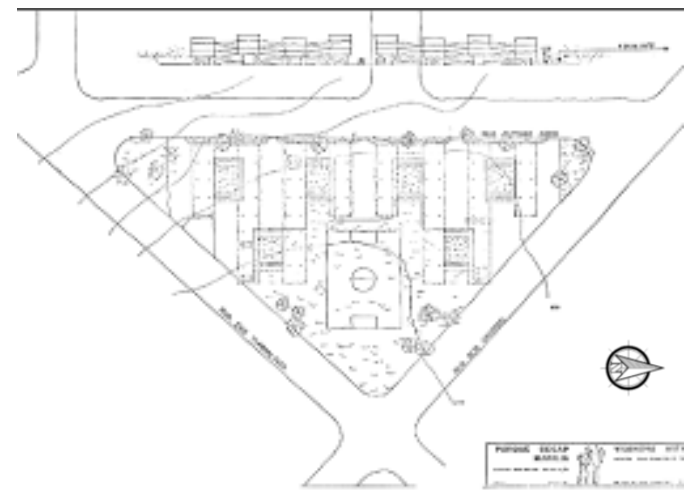

Fonte: Arquivo FAU-USP (1976). 
Figura 10 - Conjunto Cecap Mogi-Guaçu, SP, 2014 - Mogi-Guaçu/SP

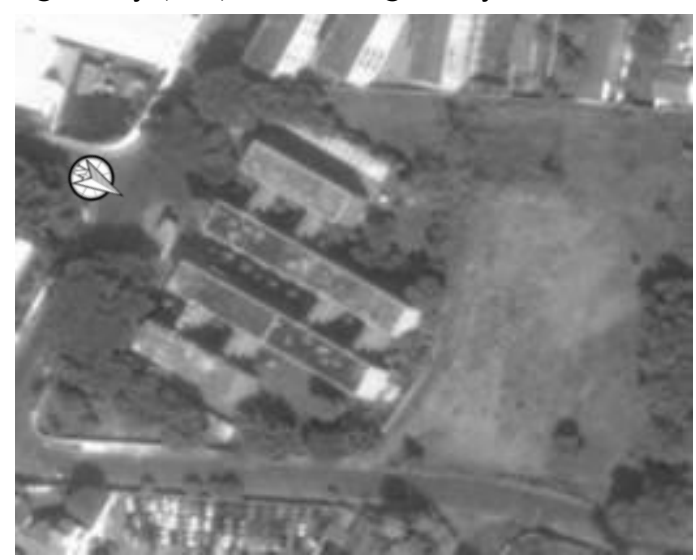

Fonte: Google Earth, adaptado pelos autores.

Figura 11 - Conjunto Cecap Mogi-Guaçu, SP, 1977 - implantação

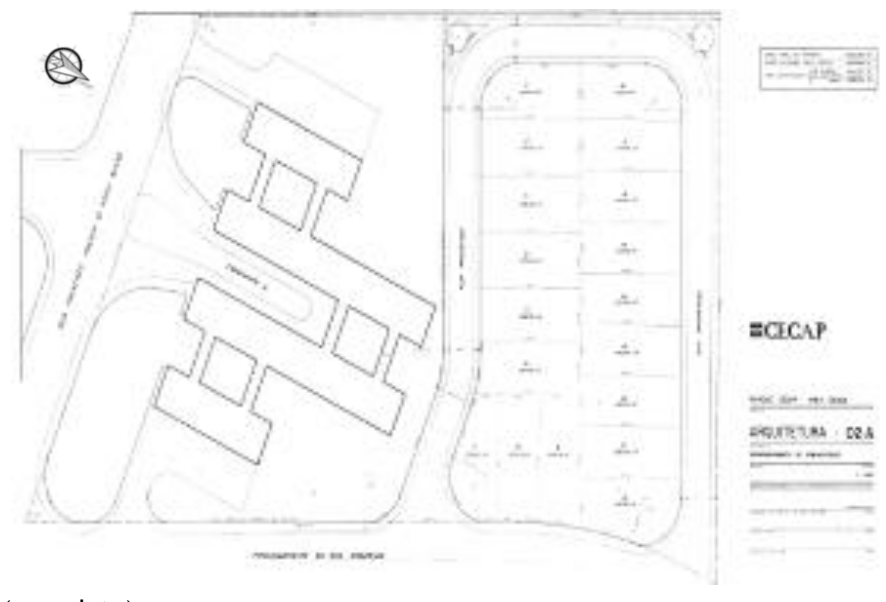

Fonte: Arquivo FAU-USP (sem data).

Figura 12 - Conjunto Cecap Jundiaí, SP - estudo preliminar - pavimento térreo

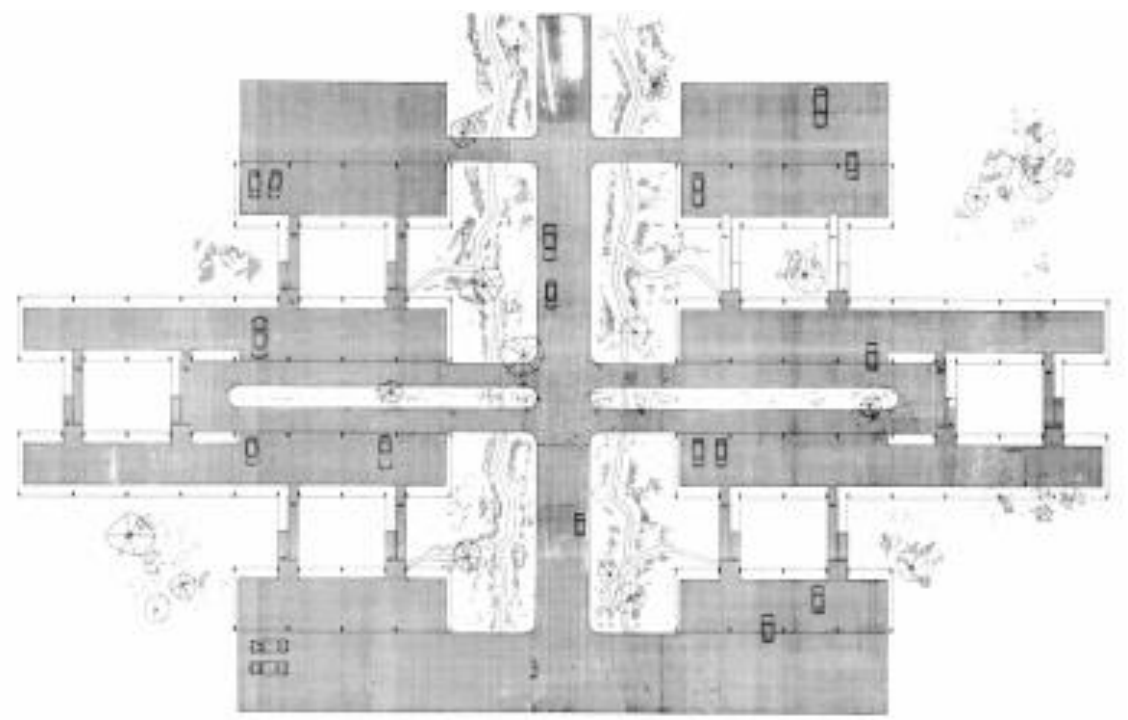

Fonte: Arquivo FAU-USP (sem data). 
Além de muito menores, os conjuntos habitacionais Cecap de Marília e Jundiaí são pouco conhecidos. Por exemplo, em depoimento a Cunha (2009), o próprio Fábio Penteado relata que “[...] houve outras experiências em outros municípios. Com o Artigas fizemos vários estudos, houve Jundiaí que me parece que foi o único feito [...]"12. Igualmente em depoimento a Cerávolo $(2007)^{13} \mathrm{o}$ arquiteto discorre a respeito do projeto para Americana e da implantação em Jundiaí, porém não se recorda dos dois últimos: "[...] teve uma implantação de uma unidade pequena em Jundiaí, eu acho que só [...]" (CERÁVOLO, 2007). Com exceção de Cunha (2009), na literatura estudada Marília e Mogi-Guaçu são citados juntamente com os projetos não executados.

Além do fato de Penteado não se recordar, as evidências encontradas permitem concluir que ele e Mendes da Rocha não tenham participação nos conjuntos de Jundiaí, Marília e Mogi-Guaçu. Nas pranchas referentes ao projeto arquitetônico desses conjuntos, é possível verificar o selo do escritório de Vilanova Artigas, constando somente o seu nome e o registro profissional. $\mathrm{O}$ livro sobre a obra de Artigas editado por Ferraz (1997) inclui Penteado como coautor em Americana e atribui a autoria de Jundiaí apenas a Artigas. Também, na listagem da obra completa de Paulo Mendes da Rocha, consta como de sua autoria somente o projeto de Guarulhos (PISANI, 2013). Como apoio a essa conclusão, um dos membros da equipe de projetos da Cecap, arquiteto Mario Luiz Savioli, em seu currículo disponível na internet ${ }^{14}$, alista os projetos dos quais participou incluindo cuidadosamente os coautores. No caso de Guarulhos (fase de 1976) constam como autores Artigas, Penteado, Visconti, Martino e equipe da Cecap; nos casos de Marília e Mogi-Guaçu, apenas Artigas e equipe da Cecap.

\section{Análise comparativa dos conjuntos}

A revisão bibliográfica e o levantamento dos projetos dos conjuntos habitacionais para a Cecap permitem a identificação de diversas variações nas soluções projetuais e construtivas entre as fases de Guarulhos e as dos demais conjuntos. Para a análise comparativa dos projetos arquitetônicos e dos conjuntos habitacionais que foram construídos,

\footnotetext{
${ }^{12}$ Depoimento de Fábio Penteado a Gabriel Rodrigues da Cunha em 10/12/2008.

${ }^{13}$ Depoimento de Fábio Penteado a Fabiana Cerávolo em 09/03/2007.

${ }^{14}$ Currículo disponível em:

<http://www.escavador.com/pessoas/626762>. Acesso em: dez 2015.
}

foram elencados os itens mais perceptíveis e que implicam em alterações formais, volumétricas, estruturais e de aparência:

(a) conformação dos conjuntos: organização dos edifícios em cada conjunto;

\section{(b) circulação vertical e adequação à}

topografia: análise das características, e soluções adotadas em cada conjunto;

(c) elementos estruturais: tipos de lajes, vigas e pilares; e

(d) vedações: alterações tanto nos projetos quanto na construção dos conjuntos.

Mário Savioli, arquiteto colaborador nos projetos para a Cecap ${ }^{15}$, destaca que o desenvolvimento do projeto de Guarulhos era "uma fábrica de conhecimentos" (CERÁVOLO, 2007, p. 192). Sobre as etapas de construção dos edifícios do conjunto de Guarulhos, Savioli ressalta ainda que "[...] cada um deles tem uma alteração no processo construtivo, ou seja, de incrementação tecnológica, no processo descobriu-se o que dava certo e o que não dava [...]"16. Diante das etapas de elaboração do projeto para Guarulhos e de sua construção, nota-se que ocorreram modificações projetuais e construtivas. Posteriormente, nos projetos dos conjuntos propostos para as demais cidades, e na execução destes, é possível notar resultados híbridos, ora aplicando soluções que haviam sido implementadas tardiamente em Guarulhos, ora retomando soluções dos projetos mais antigos. A análise dos itens elencados possibilita verificar o desenvolvimento da proposta e a reaplicação, como destacado por Savioli, daquilo 'que dava certo e o que não dava'.

Os itens descritos acima foram identificados para as análises comparativas dos conjuntos por se tratarem de características que conduziram o processo de projeto. Tais itens demonstram variações de soluções projetuais e construtivas e são significativos quanto à revelação do pensamento para a tomada das decisões. Adicionalmente, esses itens são organizados graficamente.

\section{Conformação dos conjuntos}

\section{Apartamento}

No conjunto Cecap Guarulhos o apartamento tipo possui $64,00 \mathrm{~m}^{2}$ e sua planta é composta de três dormitórios, sala, cozinha, área de serviço e banheiro. A iluminação e ventilação do banheiro ocorrem por meio de elementos vazados voltados

\footnotetext{
${ }^{15}$ Depoimento de Mário Savioli a Fabiana Cerávolo em 5/4/2007. ${ }^{16}$ Depoimento de Mário Savioli a Fabiana Cerávolo em 5/4/2007.
} 
para a área de serviço que, juntamente com cozinha e sala, têm suas janelas voltadas para o pátio interno formado pela junção dos edifícios que formam o bloco. Já os dormitórios possuem suas aberturas para iluminação e ventilação voltadas para as faces externas de cada bloco.

A tipologia dos apartamentos tipo segue idêntica em todos os projetos, foi verificada somente alteração do layout do banheiro, devido à modificação nas paredes que dividem os apartamentos, que, na primeira etapa de Guarulhos foi executada em blocos de concreto e, posteriormente, nas demais etapas de Guarulhos e nos demais conjuntos executada em concreto. A alteração da distribuição dos equipamentos no banheiro permitiu concentrar todas as instalações hidráulicas nas paredes internas que dividem banheiro, cozinha e área de serviço, o que facilita a instalação e manutenção.

A proposta da planta livre possibilitada pelos elementos de vedação interna permite a liberdade de layout (Figura 13), com possibilidade de modificação nas dimensões dos dormitórios. A utilização de planta livre permite diversas subdivisões de cômodos, adequando-se ao perfil familiar (CUNHA, 2009).

\section{Blocos de apartamentos}

É comum a todos os conjuntos a adoção de edifícios em lâmina com quatro pavimentos (térreo e mais três pavimentos) sobre pilotis, janelas horizontais que cortam toda a fachada nas duas faces dos edifícios, cobertura em laje impermeabilizada ("afogada") coberta por um espelho d'água e argila expandida, e espaçamento entre edifícios garantindo a iluminação natural em todos os apartamentos. No que diz respeito às unidades habitacionais (apartamentos), todos os conjuntos são idênticos. As diferenciações são verificadas no agrupamento dos edifícios laminares e na adoção das circulações verticais que foram alteradas em cada conjunto e no formato dos blocos.

Cada bloco do conjunto habitacional de Guarulhos é composto de dois edifícios em lâmina, unidos pela circulação vertical que forma um pátio interno para cada bloco. O pavimento tipo é formado por 10 apartamentos por edifício, num total de 20 apartamentos por andar. A composição de edifícios laminares unidos aos pares repete-se nas três etapas de construção do conjunto Cecap Guarulhos.

Nos conjuntos posteriores a proposta de edifícios lineares é mantida, porém o agrupamento dos blocos acontece de maneira diferente. Os blocos são formados por subconjuntos de quatro edifícios laminares com dimensões diferentes, sendo dois edifícios centrais de maior extensão com oito apartamentos cada um e dois edifícios externos menores que correspondem à metade dos edifícios maiores. Os edifícios estão interligados entre si por rampas alternadas. $\mathrm{O}$ espaçamento entre os edifícios laminares mantém a mesma regularidade, de aproximadamente $9 \mathrm{~m}$.

Figura 13 - Planta apartamento tipo - Conjunto Cecap Zezinho Magalhães Prado, Guarulhos, SP - planta flexível - possibilidade de layout interno

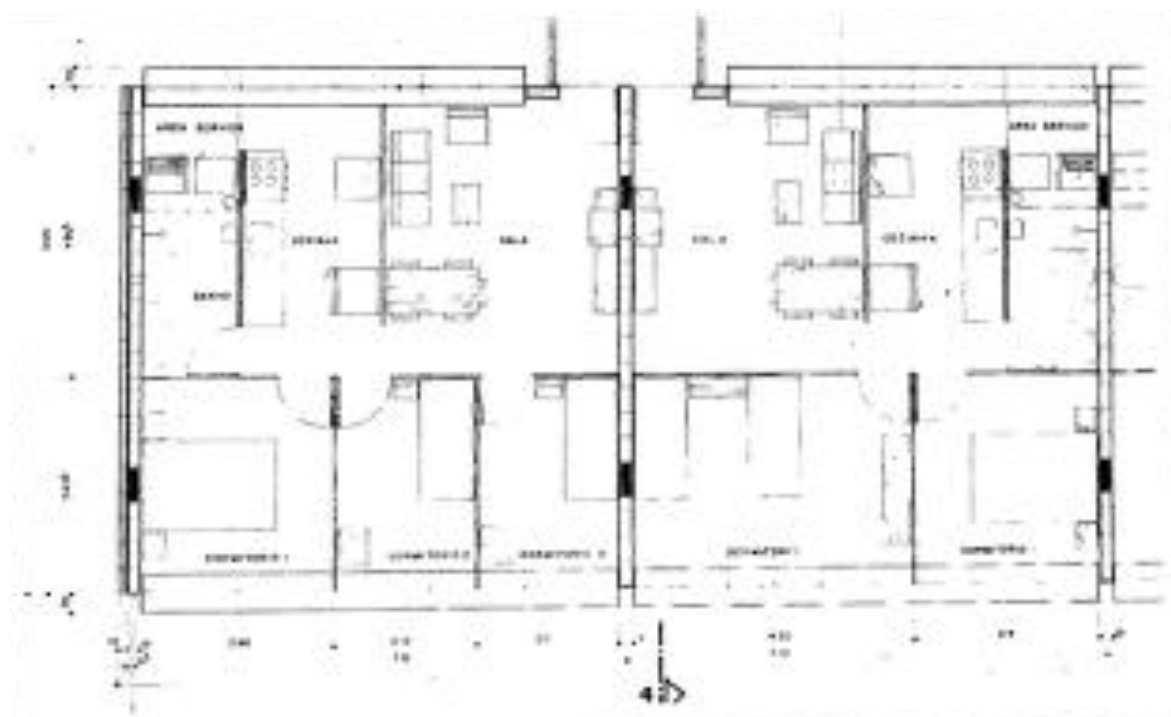

Fonte: Arquivo FAU-USP (sem data). 
A partir da segunda etapa de Guarulhos, foram adotados caixilhos de alumínio. Os originais de ferro apresentaram severa oxidação ${ }^{17}$.

\section{Circulação vertical e adequação à topografia}

A opção pela escada foi adotada nas três etapas de implantação do Conjunto Habitacional Zezinho Magalhães Prado (Figura 14), porém em cada etapa de construção ocorreram alterações quanto ao desenho e à execução.

Como visto, eram constantes as tentativas de implementar processos mais racionalizados e/ou industrializados na execução do conjunto Cecap Guarulhos. Relatos indicam uma grande contribuição de Falcão Bauer ${ }^{18}$ na promoção de controle de qualidade, economia e durabilidade, tanto de elementos estruturais como de vedação e esquadrias. Sobre as alterações nas escadas do conjunto de Guarulhos, Mário Savioli ${ }^{19}$ relata que:

[...] a mudança das escadas aconteceu da seguinte maneira: eles quiseram industrializar o conjunto, então eles montaram um sistema de formas de aço, fundiam uma laje, colocavam a forma de aço, fundiam outra laje, isso eles conseguiram resolver, o que eles não conseguiam resolver era como colocar a escada, porque se eles fundissem a escada, a lança do guindaste não conseguia colocar a escada entre os dois prédios, então o projeto da escada foi refeito várias vezes e durante muito tempo ficou da maneira artesanal (CERÁVOLO, 2007, p. 191).

As distinções entre as etapas de Guarulhos são as seguintes:

(a) $1^{\text {a }}$ etapa: a tipologia adotada segue o formato em "U" (Figura 15). As escadas são construídas com método convencional moldadas in loco, com paredes laterais em blocos de concreto aparente e duto central para lixo e quadro de distribuição elétrica;

(b) $2^{\mathrm{a}}$ etapa: acontece a alteração da tipologia adotada nesta fase. As escadas passam a ser em lance único, moldadas in loco com uso de formas metálicas; (c) $3^{\text {a }}$ etapa: mantém-se a adoção da escada em lance único, agora pré-fabricada em concreto. A alteração visual em relação à etapa anterior se dá pelo guarda-corpo vazado, que torna a peça mais leve e facilita o transporte e a montagem.

Nos conjuntos posteriores foram adotadas definitivamente as rampas como circulação vertical, seguindo o que foi proposto para o conjunto de Americana. Assim como nas obras anteriores de Artigas, a declividade supera $16 \%$. Embora excessiva para a circulação autônoma de pessoas em cadeiras de rodas, essa declividade é confortável e resulta numa extensão de percurso aceitável. Tal solução implicava naturalmente no escalonamento dos blocos em meios níveis. Em todos os casos as rampas foram executadas de modo convencional, in loco (Figura 16).

Os itens Organização da Planta e Circulação Vertical encontram-se representados graficamente na Figura 17

No conjunto Cecap Guarulhos a topografia foi trabalhada de maneira que possibilitasse a implantação dos blocos em trechos planos, em todo o conjunto. A ocorrência de desníveis no conjunto se fez nos jardins entre cada bloco construído, e em sua grande maioria não há grandes desníveis entre os blocos.

O terreno onde está implantado o conjunto em Jundiaí apresenta declividade acentuada. Verificando in loco, pôde-se constatar um desnível considerável entre o terreno de implantação do Condomínio Cerejeira, por exemplo, em relação ao lote que faz divisa com os fundos. A topografia em Jundiaí justifica a implantação dos edifícios em níveis diferentes, além de mostrar-se como opção mais adequada. Entretanto, o desnível acentuado, conforme observado, indica grande modificação no terreno, mas não é possível afirmar se esse desnível foi realizado para a implantação do conjunto, devido a intervenções urbanísticas para implantação de loteamentos próximos, ou se já se encontrava dessa maneira quando da construção do conjunto.

\footnotetext{
${ }^{17}$ Depoimento de Fernando Gonçalves a Fabiana Cerávolo em 05/05/2007.

${ }^{18} \mathrm{~A}$ empresa L Falcão Bauer Ltda. era a responsável pelo orçamento e pela programação da obra de Guarulhos (CÉRÁVOLO, 2007).

${ }^{19}$ Depoimento de Mário Savioli a Fabiana Cerávolo em 5/4/2007.
}

180 Augusto, W. F. C.; Guadanhim, S. J. 
Figura 14 - Conjunto Cecap Zezinho Magalhães Prado - Guarulhos, SP - caixas de escada - (a) $1^{\text {a }}$ Etapa (1968-1972), (b) $2^{\text {a }}$ Etapa (1972-1976) e (c) $3^{\text {a }}$ Etapa (1978-1981)

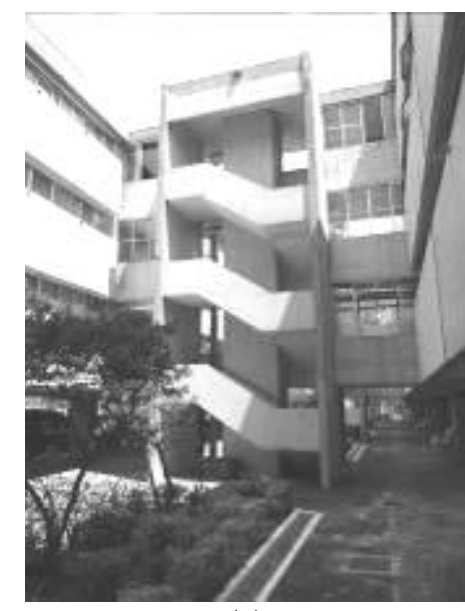

(a)

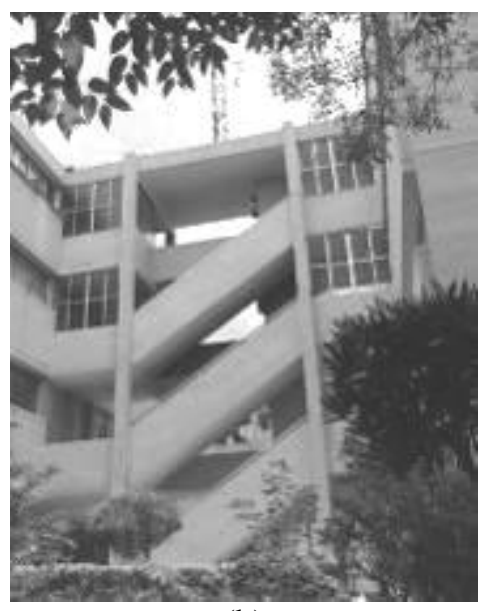

(b)

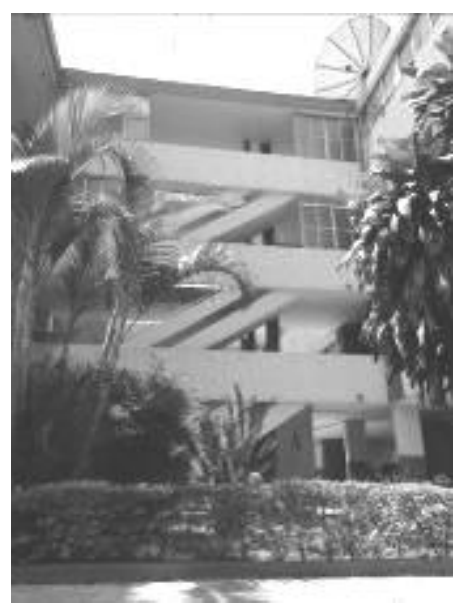

(c)

Figura 15 - Conjunto Cecap Guarulhos - elevação 1 e 2

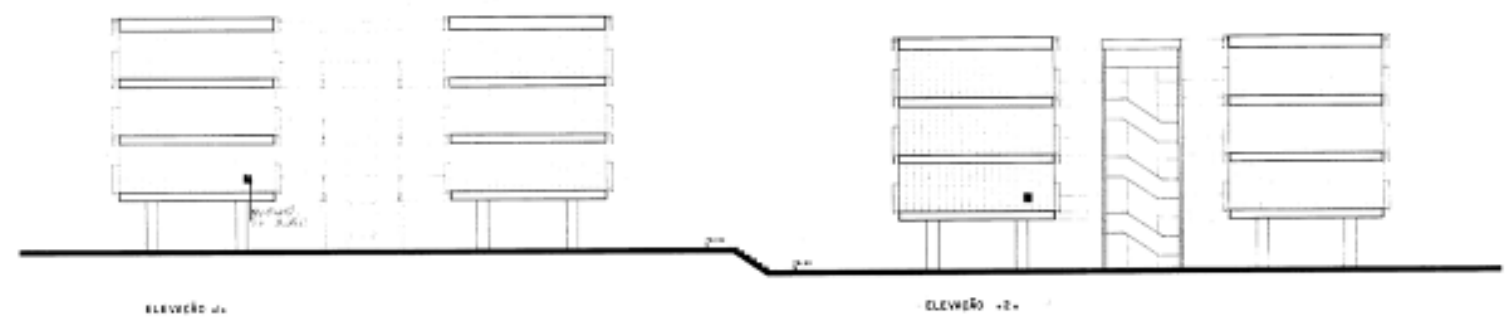

Fonte: Arquivo FAU - USP (sem data).

Figura 16 - Circulação vertical em rampas - (a) Conjunto Cecap Jundiaí, SP e (b) Conjunto Cecap Maria Izabel Marília, SP

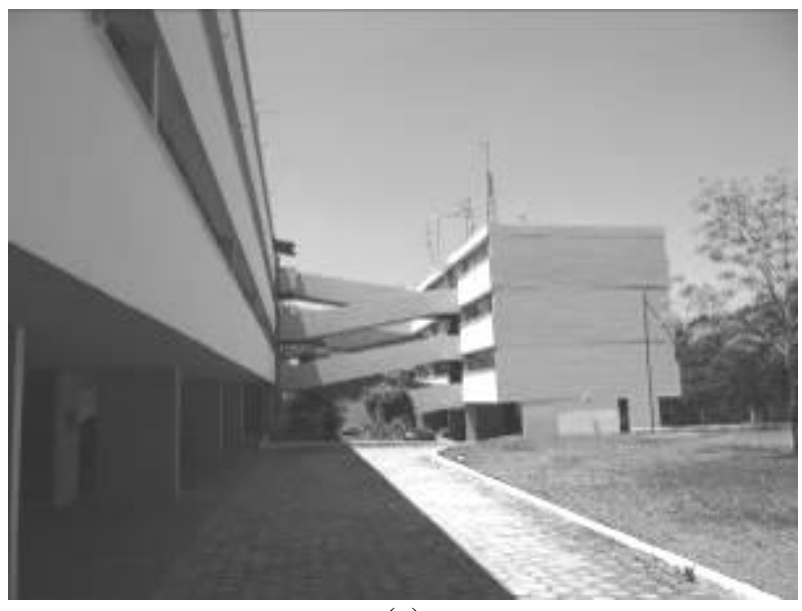

(a)

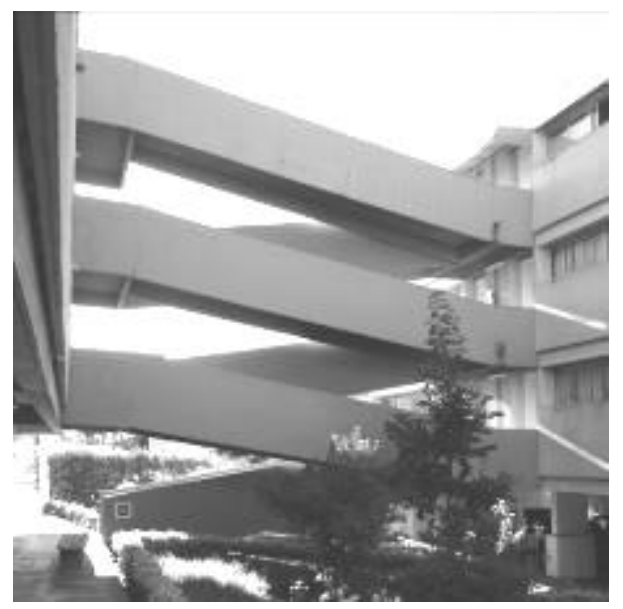

(b) 
Figura 17 - Quadro comparativo - esquema gráfico dos elementos de análise: organização da planta e circulação vertical

Organização da planta

Guarulhos

1a. etapa

1968-72

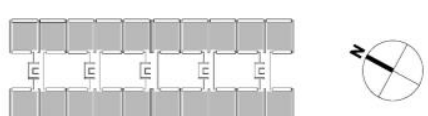

Circulação vertical

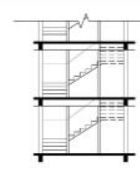

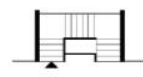

Guarulhos

2a. etapa

1972-76
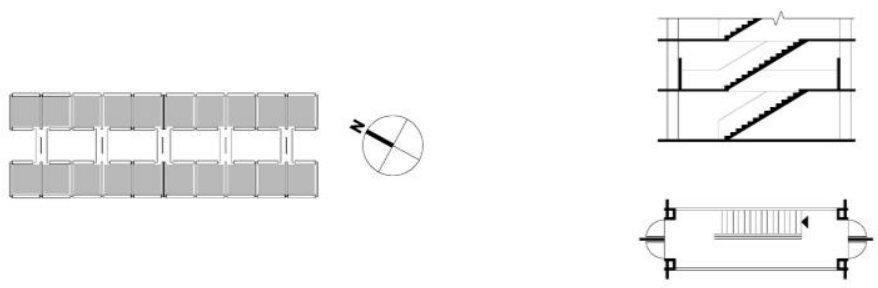

Guarulhos

3a. etapa

1978-81
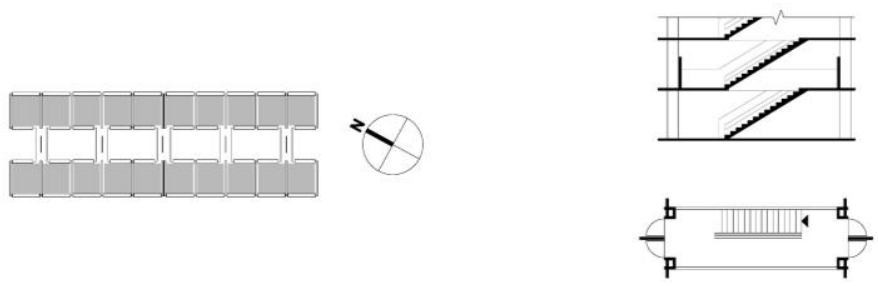

Jundiaí

1973
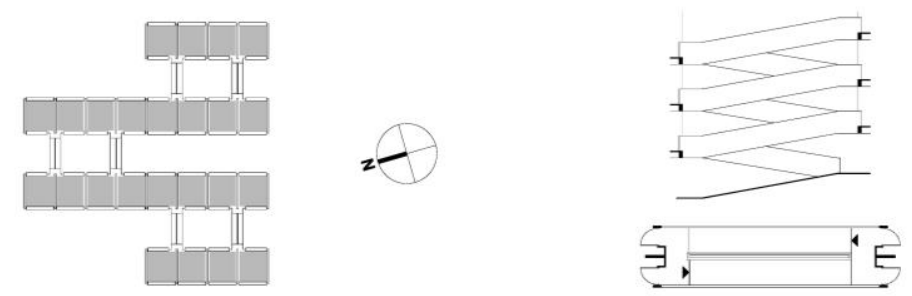

Marília

1976-78
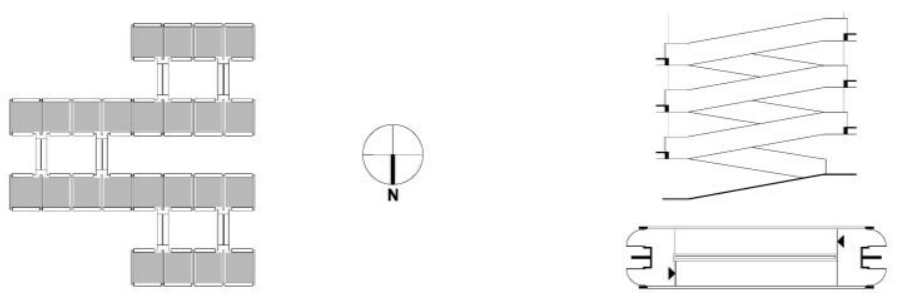

Mogi-Guaçu
1977
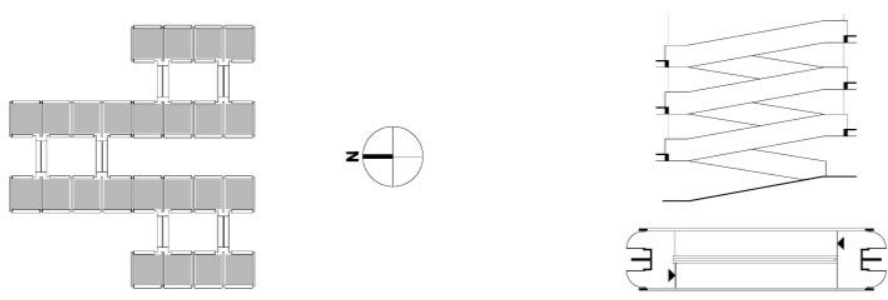
No caso particular de Marília (Figura 18), chama atenção a artificialidade do emprego da implantação em meios níveis, uma vez que o relevo é praticamente plano, o que obriga a execução de um movimento de terra aparentemente desnecessário. Os blocos ficam em cotas alternadas (Figura 19), não acompanhando naturalmente o relevo como no caso de Jundiaí (Figura 20). Isso poderia levar à conclusão de que simplesmente o projeto de Jundiaí foi reaproveitado, apenas encaixando-o no terreno. Porém existe no acervo de Artigas na FAUUSP um estudo de implantação com pequenos volumes de isopor sobre o terreno plano (Figuras 21 e 22), o que indica claramente a preocupação dos arquitetos com a validade e viabilidade as proposta e, principalmente, com a tomada decisão consciente quanto a esse aspecto.

Figura 18 - Vista geral do conjunto Cecap Maria Izabel $(1978)^{20}$, Marília, SP

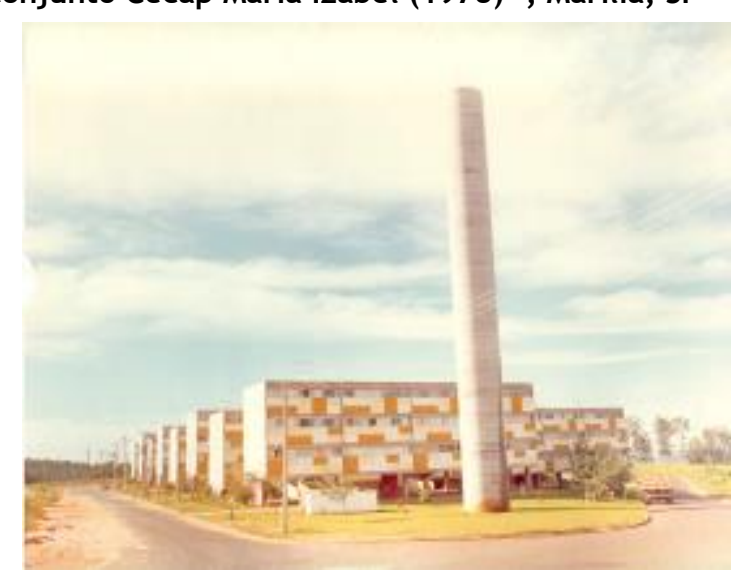

Fonte: Arquivo FAU - USP (1978).

Figura 19 - Conjunto Cecap Maria Izabel, Marília, SP - corte BB

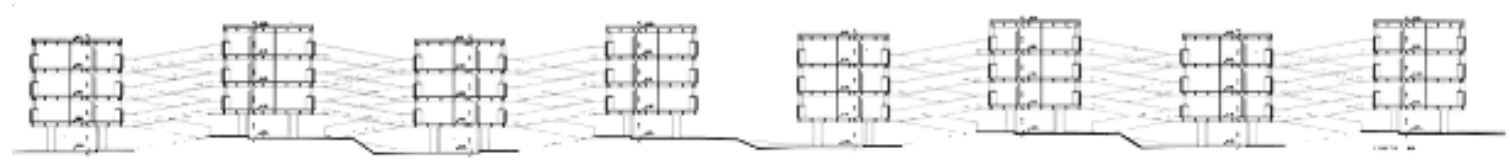

Fonte: Arquivo FAU-USP (sem data).

Figura 20 - Conjunto Cecap Jundiaí, SP - corte B

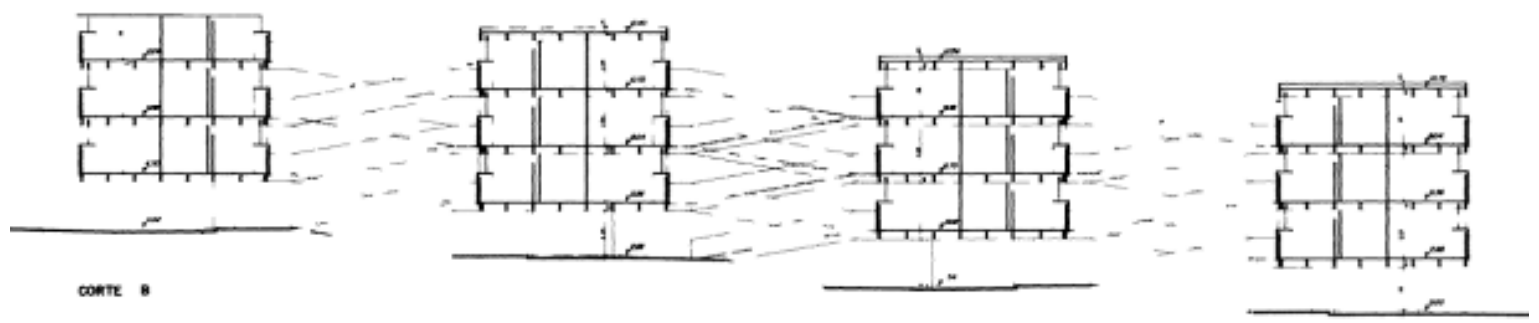

Fonte: Arquivo FAU - USP (sem data).

\footnotetext{
${ }^{20} \mathrm{O}$ arquivo da FAU-USP não faz referência à data da foto apresentada. Estima-se que ela date de 1978, ano de conclusão do conjunto Cecap Maria Izabel.
} 


\section{Figura 21 - Conjunto Cecap Maria Izabel, Marília, SP - estudo volumétrico implantação}

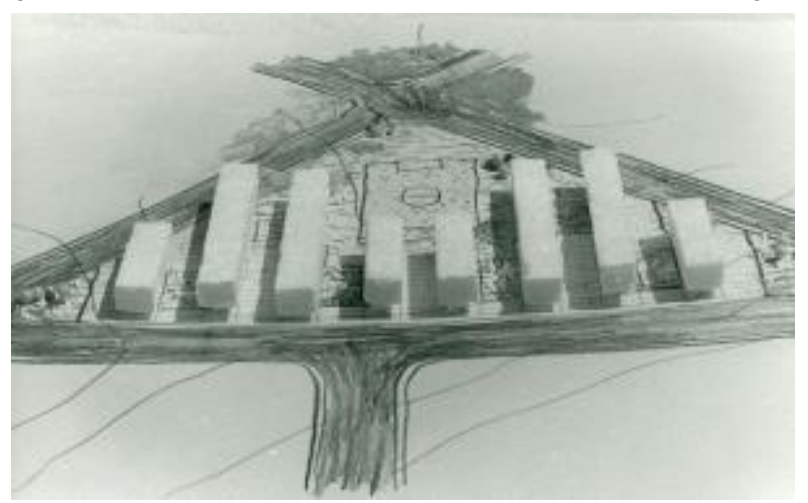

Fonte: Arquivo FAU-USP (sem data).

Figura 22 - Conjunto Cecap Maria Izabel, Marília, SP - estudo volumétrico implantação - vista em perspectiva

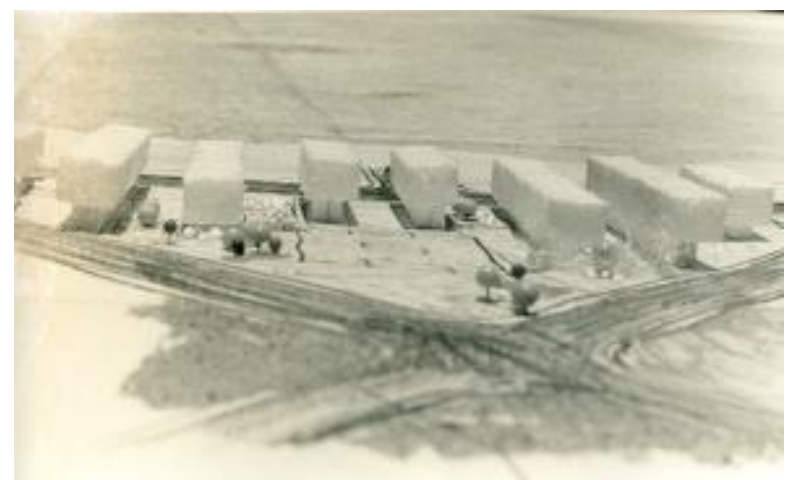

Fonte: Arquivo FAU-USP (sem data).

Em Mogi-Guaçu o terreno possui declividade suave (cerca de $10 \%$ ) e a solução em meios níveis mostra-se acertada, o que permite acomodação natural dos blocos e transição suave entre os platôs.
As representações gráficas referentes à adequação à topografia nos conjuntos Cecap de Guarulhos, Jundiaí, Marília e Mogi-Guaçu são identificadas na Figura 23. 
Figura 23 - Quadro comparativo - esquema gráfico dos elementos de análise: adequação à topografia Implantação: cortes esquemáticos

Guarulhos 1a. etapa 1968-72

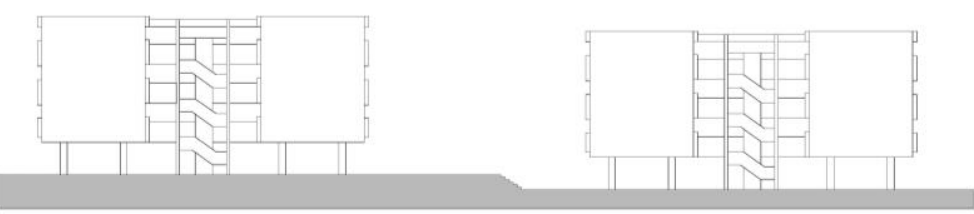

Guarulhos

2a. etapa

1972-76

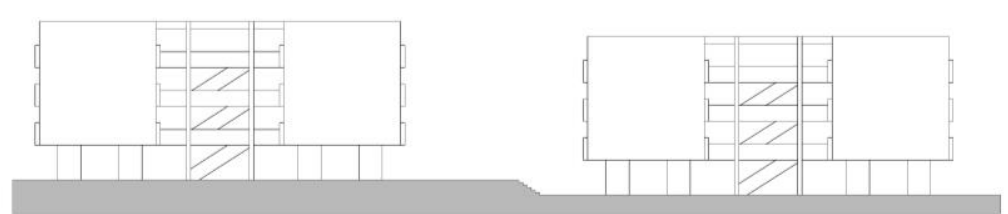

Guarulhos

3a. etapa

1978-81
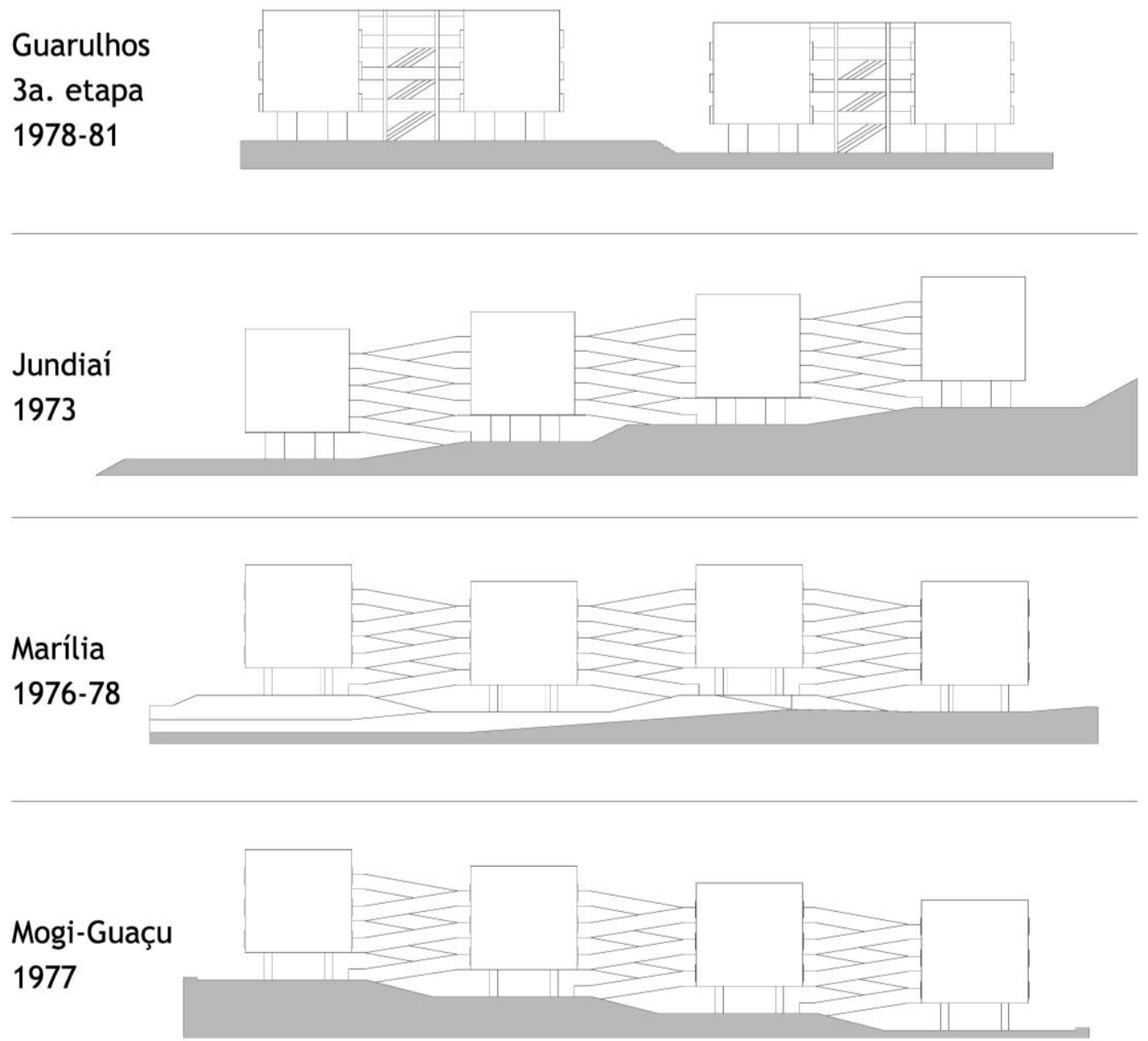


\section{Elementos estruturais}

\section{Pilares}

Os pilares são elementos arquitetônicos marcantes nos conjuntos (Figura 24). Há contato muito próximo dos usuários com tais elementos estruturais devido à adoção de pilotis. São observadas diferenças na execução de cada etapa de construção do conjunto em Guarulhos, conforme segue: (a) $1^{\mathrm{a}}$ Etapa (1968-1972) - a locação dos pilares no pavimento térreo acompanha a distribuição dos apartamentos nos pavimentos superiores, onde os pilares foram distribuídos aos pares, localizados nas divisas dos apartamentos, distanciados entre si a aproximadamente $7 \mathrm{~m}$ (sentido longitudinal do bloco). Essa distribuição permitiu um espaço para três vagas de estacionamento. Os pilares foram executados nas dimensões de $19 \mathrm{~cm} \mathrm{x} 60 \mathrm{~cm}$, distanciados $140 \mathrm{~cm}$ das extremidades dos blocos e $4 \mathrm{~m}$ entre pilares; (b) $2^{\mathrm{a}}$ Etapa (1972-1976) e $3^{\mathrm{a}}$ Etapa (1978-1981) - mantém-se a mesma locação que respeita a distribuição dos apartamentos nos pavimentos, porém os pilares se tornaram mais robustos, medindo $19 \mathrm{~cm}$ x $120 \mathrm{~cm}$, distantes 75 $\mathrm{cm}$ das fachadas dos edifícios. Essa alteração é decorrência da nova solução para as lajes. As originais lajes nervuradas "pi" deram lugar a lajes planas, sem vigas, concretadas sobre formas metálicas e curadas a vapor (2 ${ }^{\mathrm{a}}$ Etapa) e com sistema de formas em túnel "Outinord" ( $3^{\text {a }}$ Etapa). Naturalmente, devido à ausência de vigas, o contraventamento da estrutura exigiu maior resistência dos pilares.

Em Jundiaí (c), os pilares foram executados iguais aos da segunda e terceira etapas de Guarulhos (19 $\mathrm{cm} \times 120 \mathrm{~cm}$ ) e as lajes são lisas, sem nervuras. Porém, no projeto arquitetônico, desde os desenhos preliminares verifica-se que os desenhos dos pilares assemelham-se aos propostos para a primeira etapa de Guarulhos (19 cm x $60 \mathrm{~cm})$. Além disso, nesses desenhos, sua locação é no alinhamento externo dos edifícios laminares, sem balanço. Assim como na primeira etapa de Guarulhos, os pilares mais esbeltos aparecem juntamente com as lajes nervuradas em "pi".

As pranchas do projeto do conjunto Cecap Jundiaí datam de outubro de 1974, período que coincide com a execução da segunda etapa do conjunto
Cecap de Guarulhos. Isso significa que as experiências obtidas durante a execução da segunda etapa de Guarulhos foram aplicadas em Jundiaí. É possível supor que dois fatores foram determinantes para a mudança: a velocidade e economia do sistema estrutural de lajes planas concretadas com formas metálicas e a proximidade entre Guarulhos e Jundiaí (cerca de $75 \mathrm{Km}$ ) possivelmente viabilizou a utilização da mesma tecnologia de formas metálicas.

Em Marília, o projeto arquitetônico apresenta pilares de seção semelhante à primeira etapa de Guarulhos, porém a execução ocorreu de maneira diferente dos demais conjuntos, sendo executados com seção de $19 \mathrm{~cm}$ x $70 \mathrm{~cm}$, porém a diferença encontrada é a execução de uma "base" alargada nos pilares até uma altura de $1,10 \mathrm{~m}$. Para essa "base" não foram encontradas informações concretas que justificassem sua existência.

O projeto de Marília data do período de 1976 a 1978, que compreende o final da segunda etapa e início da terceira etapa de construção do conjunto de Guarulhos. As experiências com formas metálicas e mudanças nas lajes e dimensões dos pilares, que foram aplicadas no conjunto Cecap Jundiaí, não ocorreram em Marília (d): exceto pelo alargamento da base dos pilares, eles foram executados de acordo com o que fora realizado durante a primeira etapa de construção do conjunto Zezinho Magalhães Prado, bem como com o sistema de lajes nervuradas em "pi" e formas tradicionais. É possível que o porte do empreendimento e a distância da capital não justificassem o investimento em sistemas mais industrializados. É importante lembrar inclusive o papel das construtoras que ganhavam as licitações. No caso de Marília a vencedora foi uma empresa local, construtora San Carlo, o que corrobora essa conclusão.

Em Mogi-Guaçu (e), não obstante a proximidade à capital, verifica-se a mesma situação de Marília, exceto pela base alargada dos pilares. O conjunto é ainda menor, portanto a utilização de formas metálicas não foi adotada. A estrutura foi executada totalmente em técnica convencional, mantendo o sistema de lajes nervuradas, como no projeto original de Guarulhos. 


\section{Figura 24 - Pilotis}

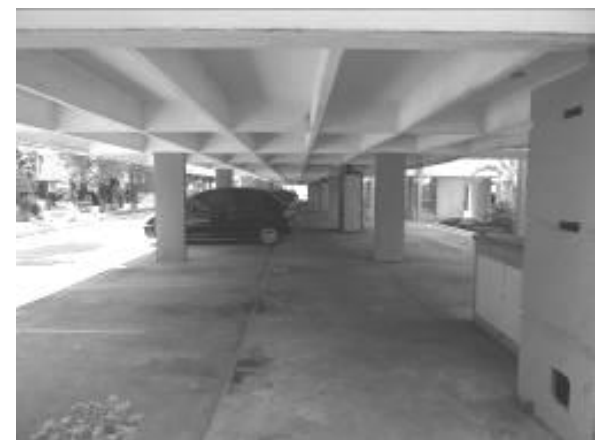

(a) Conjunto Cecap Guarulhos, SP - $1^{\mathrm{a}}$ Etapa (1968-1972)

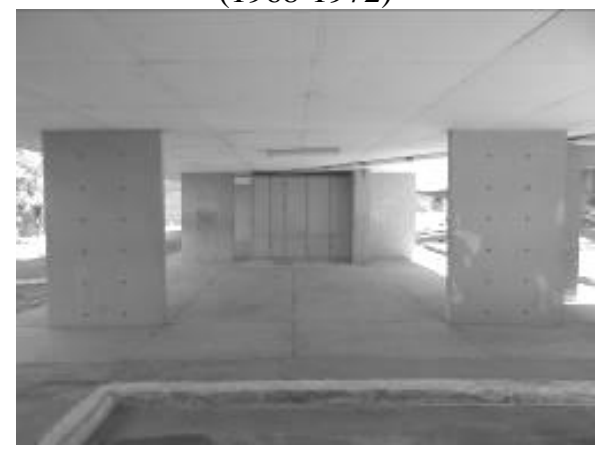

(c) Conjunto Cecap Jundiaí, SP

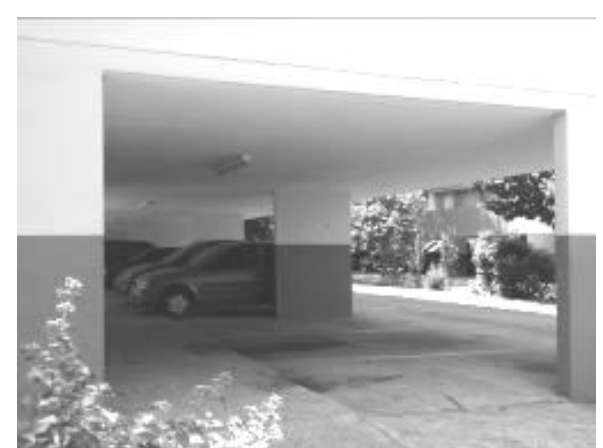

(b) Conjunto Cecap Guarulhos, SP - $3^{\mathrm{a}}$ Etapa

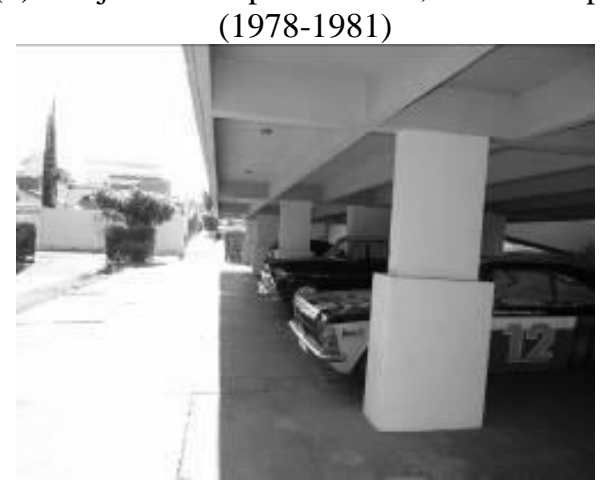

(d) Conjunto Cecap Marília, SP

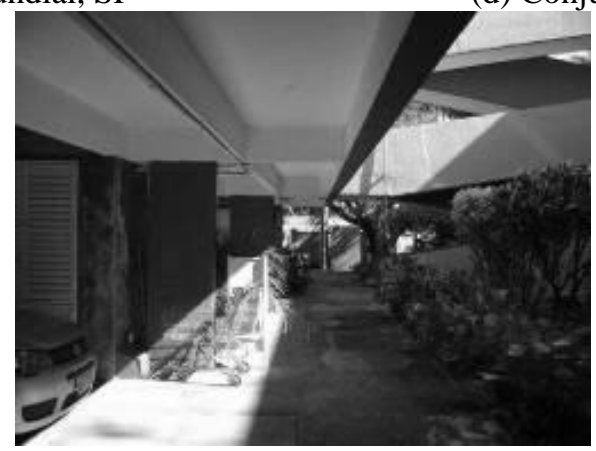

(e) Conjunto Cecap Mogi-Guaçu, SP 
Figura 25 - Quadro comparativo - esquema gráfico dos elementos de análise: pilares e estrutura

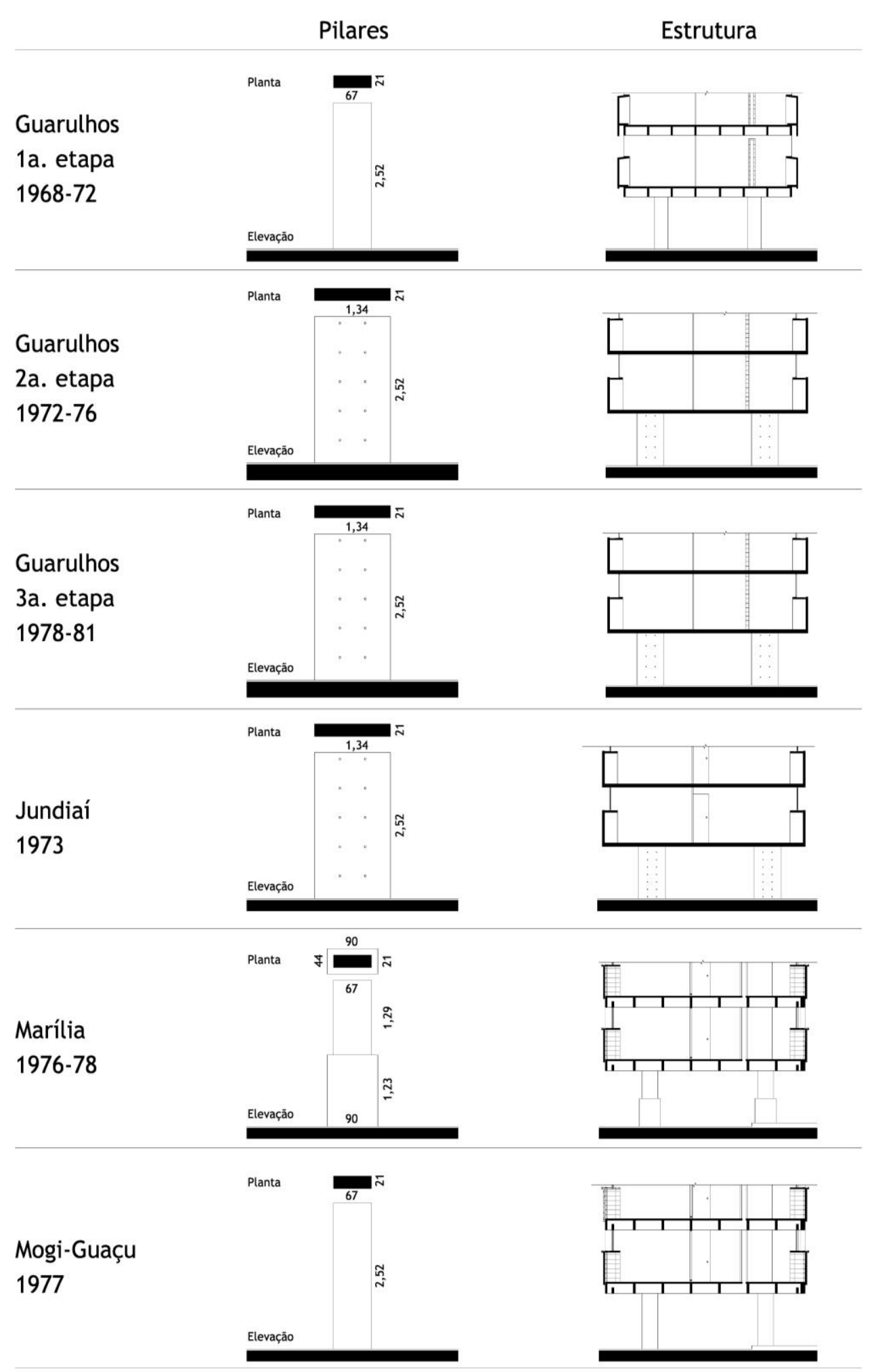


Lajes

No Conjunto Zezinho Magalhães Prado, os elementos estruturais sofreram alterações tanto projetuais quanto durante as etapas de execução. Durante a primeira etapa da construção, verifica-se no projeto arquitetônico a proposta de vigas de concreto convencionais distribuídas na seção transversal dos edifícios laminares, que foram espaçadas de eixo a eixo, a cada metro, possuem altura de $45 \mathrm{~cm}$ e permitem um pé-direito livre de $2,20 \mathrm{~m}$ nos $1^{\circ}, 2^{\circ}$ e $3^{\circ}$ pavimentos e de $2,25 \mathrm{~m}$ no pavimento térreo. As vigas executadas no $3^{\circ}$ pavimento nas faces externas dos edifícios possuem altura de $65 \mathrm{~cm}$ e formam as platibandas de fechamento que constituem as caixas das coberturas.

Durante a segunda e terceira etapas de Guarulhos, as vigas internas foram eliminadas e as lajes planas executadas em concreto ${ }^{21}$, o que possibilitou um pé-direito livre nos $1^{\circ}, 2^{\circ}$ e $3^{\circ}$ pavimentos de 2,40 $\mathrm{m}$ e manteve-se o pé-direito de $2,25 \mathrm{~m}$ no pavimento térreo. Já as vigas superiores que arrematam o $3^{\circ}$ pavimento e formam as platibandas passaram a ser executadas com altura de $45 \mathrm{~cm}$.

A estrutura executada em Jundiaí assemelha-se à de Guarulhos durante sua segunda etapa de implantação. Porém, as pranchas do projeto arquitetônico, datadas de outubro de 1974, apresentam nos cortes as mesmas soluções que haviam sido colocadas em prática durante a primeira etapa do conjunto Cecap Guarulhos. Ou seja, Jundiaí fora projetado com base nas soluções mais convencionais, mas, diante das experiências bem sucedidas na segunda etapa da construção de Guarulhos, sofreu alterações. Como supramencionado, a proximidade de Guarulhos e a simultaneidade da execução possibilitaram a incorporação das soluções mais avançadas.

Nos conjuntos Cecap de Marília e Mogi-Guaçu a execução se deu de maneira tradicional, ou seja, com as vigas de concreto moldadas in loco, aparentes nos pavimentos e liberando um pédireito livre de $2,20 \mathrm{~m}$ de acordo com o projeto arquitetônico similar à primeira etapa de execução de Guarulhos. Considerando a existência dos projetos detalhados, certamente, diante do contexto e da mão de obra disponível nas cidades na época, a opção pelas técnicas construtivas tradicionais acabou se mostrando a melhor maneira de viabilizar a implantação do conjunto habitacional. Para melhor compreensão, reuniram-se

${ }^{21} 2^{\mathrm{a}}$ Etapa: utilização de formas metálicas e cura a vapor. $3^{\mathrm{a}}$ Etapa: a licitação foi vencida com a proposta de utilização de formas metálicas em "U", sistema "Outinord". graficamente os elementos estruturais na Figura 25 .

\section{Vedações}

\section{Empenas e paredes entre unidades}

Em relação às empenas laterais e às paredes entre apartamentos propostas e realizadas no conjunto Cecap Guarulhos, é possível notar diferenças nas três etapas de construção do conjunto. Na primeira etapa foram projetadas e executadas em bloco de concreto, já na segunda e terceira etapas foram propostas em projeto e executadas em concreto moldado in loco.

O espaço interno de cada apartamento tem como áreas fixas somente o banheiro, a área de serviços e a cozinha, que foram projetadas para serem executadas em bloco de concreto e concentram a instalação hidráulica dos apartamentos. As vedações internas modificaram-se após a primeira etapa, de acordo com Maria Giselda Cardoso Visconti: "[...] na primeira etapa foram utilizadas divisórias de fórmica e nas outras placas de gesso $[\ldots]^{, 22}$

Nas pranchas do projeto do conjunto Cecap Jundiaí não foi possível identificar referências sobre $o$ fato de que as vedações externas (empenas) foram projetadas para serem executadas em blocos de concreto, de acordo com a execução da primeira etapa de Guarulhos ou em concreto moldado in loco. Entretanto, foram executadas em concreto, conforme realizado na segunda e terceira etapas de execução de Guarulhos.

Em Marília e Mogi-Guaçu os projetos já previam a execução das empenas e paredes entre unidades em concreto e assim se deu a execução: "Isso aqui é uma fortaleza. As paredes de divisórias entre os apartamentos são cortinas de concreto [...]", comenta o arquiteto Waldemir Silveira, funcionário da San Carlo Engenharia na época da construção em Marília ${ }^{23}$. Isso revela que esses dois conjuntos menores constituem-se projetos híbridos, adequando-se ao contexto e incorporando as soluções possíveis que já haviam sido testadas nos projetos anteriores

As vedações internas nos conjuntos de Jundiaí e Marília foram propostas e executadas em painéis de gesso e a parede divisória entre banheiro e lavanderia foi executada em blocos de concreto, onde se concentram as instalações de água e esgoto dos apartamentos, assim como no conjunto Cecap Guarulhos.

\footnotetext{
${ }^{22}$ Depoimento de Maria Giselda Cardoso Visconti a Fabiana Cerávolo em 9/4/2007.

${ }^{23} \mathrm{Em}$ entrevista ao autor em 10 de julho de 2013.
} 


\section{Armários}

No projeto do conjunto Cecap Zezinho Magalhães Prado, propôs-se inicialmente um painel modular pré-moldado de fechamento para as fachadas externas que, ao mesmo tempo, funcionaria como armários internos aos dormitórios, sala, cozinha e lavanderia. Tal proposta permitia recuar as esquadrias e possibilitar sombreamento que protege a fachada (ZEIN, 2005). Apesar de inviabilizada a pré-fabricação, como visto, a solução foi mantida, porém executada de modo diferente, variando em cada etapa:

(a) $1^{\mathrm{a}}$ etapa - fechamento externo dos armários executado em bloco de concreto e os avanços nas fachadas possibilitados através de viga de concreto. A execução dos armários encontra-se segmentada na extensão de cada apartamento;

(b) $2^{\mathrm{a}}$ etapa - os armários possuem seu fechamento externo em painéis de concreto moldado in loco, e o avanço dos armários foi realizado mediante prolongamento das lajes de concreto de cada pavimento. Mantém-se a segmentação da extensão dos armários ao comprimento de cada apartamento; e

(c) $3^{\mathrm{a}}$ etapa - a execução dos armários mantém-se idêntica à efetuada durante a segunda etapa, porém nesta etapa os armários não foram segmentados em cada apartamento, mas executados como uma viga contínua em toda a extensão dos edifícios laminares. Em relação às empenas laterais, a projeção é de apenas $10 \mathrm{~cm}$, enquanto nas anteriores era de $30 \mathrm{~cm}$.

Particularmente com relação à terceira etapa, na qual o fechamento dos armários passou a ser feito com viga de concreto integrante da estrutura do prédio, houve a possibilidade de que sua execução fosse realizada de forma contínua. Sobre esse item, Mário Savioli relata que:

[...] o que naquele tempo era alvenaria e fazia os fechamentos dos armários externos daquelas faces coloridas, passou a ser uma viga de concreto que fazia parte da estrutura do prédio, então os armários foram de tal maneira assimilados pelo apartamento, o fechamento dele, foi a própria viga de concreto que passou a sustentar o prédio, isso já nessa última fase, tanto que alguns detalhes deixaram de existir, esses armários eram segmentados, eles passaram a serem contínuos, e essa foi a montagem dessa última fase ${ }^{24}$. (CERÁVOLO, 2007, p. 191).
Em Jundiaí mantém-se o partido arquitetônico com a adoção dos avanços que formam os armários. Em projeto é possível notar sua segmentação a cada extensão do apartamento, porém sua execução se deu de maneira contínua e com vedação externa em concreto, assim como a terceira etapa na construção de Guarulhos, o que corrobora as conclusões mencionadas no item Elementos Estruturais.

Em Marília, nota-se uma solução híbrida e mais complexa nos armários, que difere de todos os outros conjuntos. Em projeto é possível observar que o fechamento dos armários foi proposto em blocos de concreto com painel externo paralelo em concreto e assim foi executado. Nota-se então mescla do que fora executado na primeira e segunda etapas de Guarulhos. Em sua extensão, os armários foram segmentados no limite de cada apartamento, semelhante à primeira etapa de Guarulhos.

No caso de Mogi-Guaçu, o projeto repete o detalhe híbrido de Marília, porém a execução não ocorreu como projetada: adotou-se uma viga contínua moldada in loco, semelhante à da terceira etapa de Guarulhos e de Jundiaí, porém sem a projeção de $10 \mathrm{~cm}$ em relação às empenas. Claramente indica uma decisão de obra, visando a simplificação e facilidade de execução. $O$ resultado plástico, contudo, é prejudicado, tornando as fachadas mais lisas e sem detalhes. O contraste pode ser visto nas Figuras 26 e 27.

${ }^{24}$ Depoimento de Mário Savioli a Fabiana Cerávolo em 05/04/2007. 
Figura 26 - Vista externa dos armários - conjunto Cecap Guarulhos, SP

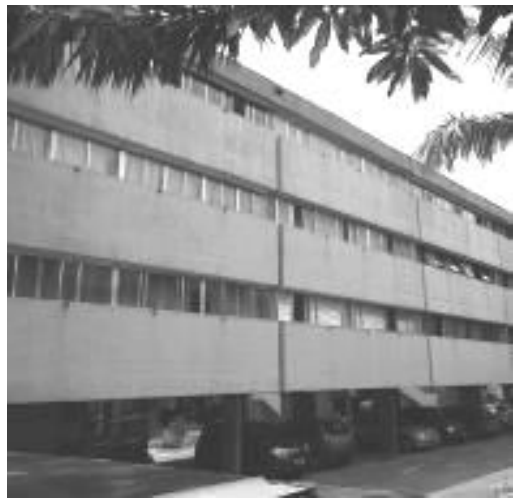

(a) $1^{\mathrm{a}}$ Etapa $(1968-1972)$

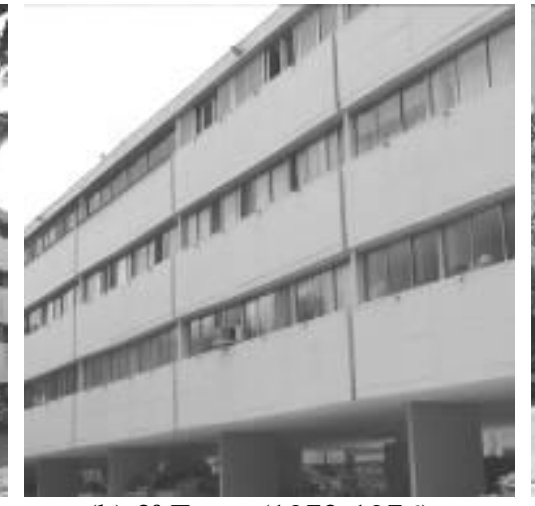

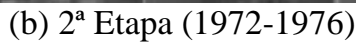

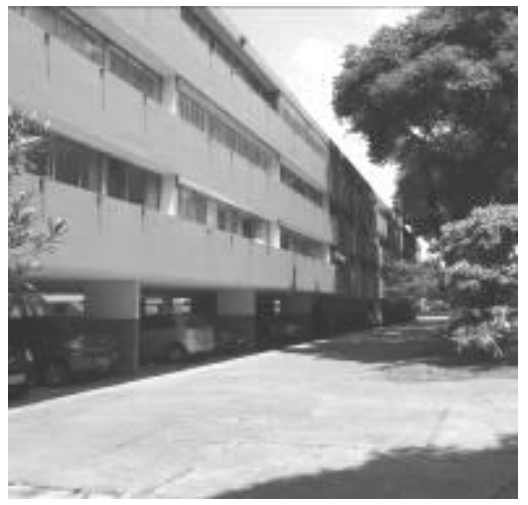

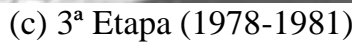

Figura 27 - Vista externa dos armários

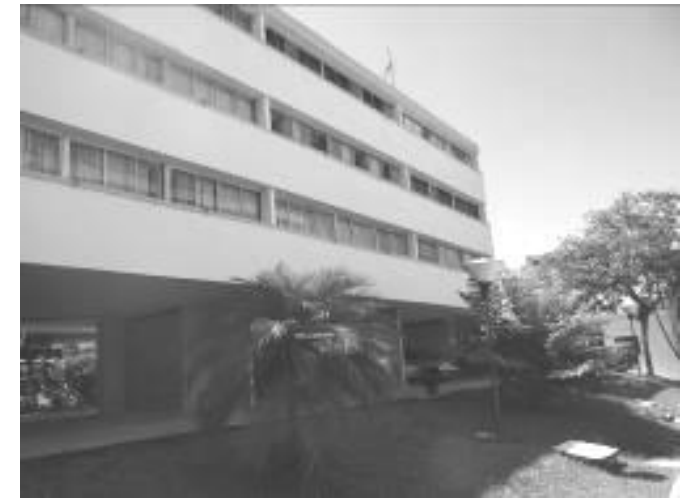

(a) Conjunto Cecap Jundiaí, SP

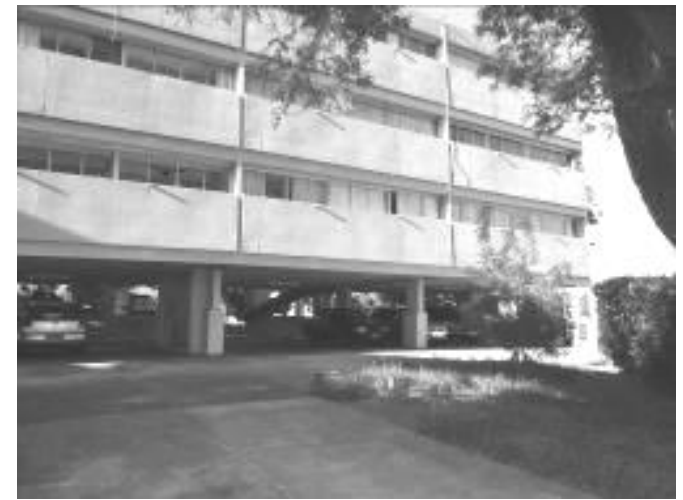

(b) Conjunto Cecap Marília, SP

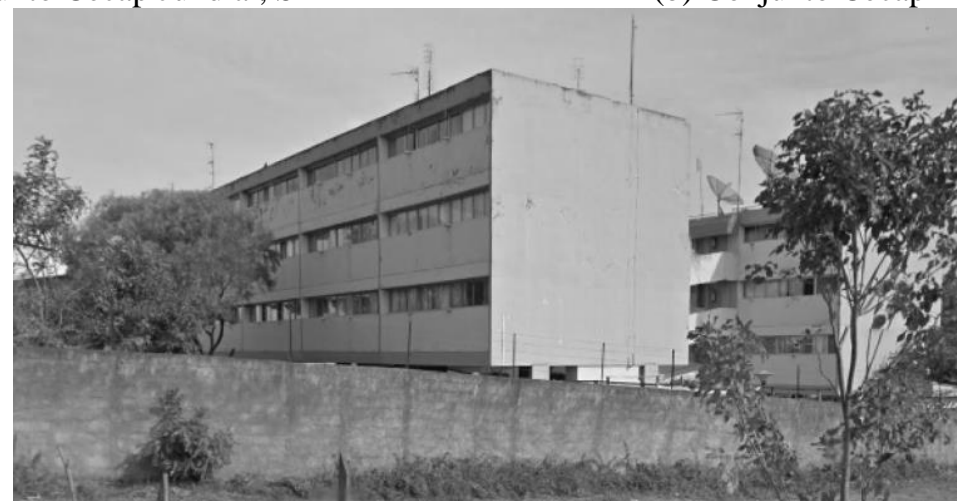

(c) Conjunto Cecap Mogi-Guaçu/SP

A seguir, as semelhanças e diferenças nas vedações externas, internas e nos armários que compõem as fachadas dos conjuntos são demonstradas por representação gráfica na Figura 28.

\section{Considerações finais}

O projeto do Conjunto Habitacional Zezinho Magalhães Prado em Guarulhos foi a primeira experiência da Cecap em implantação de conjuntos de grande porte. Colocado como questão urbana, contribuiu para reforçar paradigmas que se estabeleciam, tornando-se um dos projetos mais emblemáticos da Escola Paulista e da produção de habitação de interesse social no Brasil (ZEIN, 2005). O papel desempenhado por Vilanova Artigas, Fábio Penteado e Paulo Mendes da Rocha foi fundamental para a proposição de projetos que, além de atender à demanda por habitações, tinham como preocupações a racionalidade, a economia e a qualidade. 
Figura 28 - Quadro comparativo - esquema gráfico dos elementos de análise: vedação

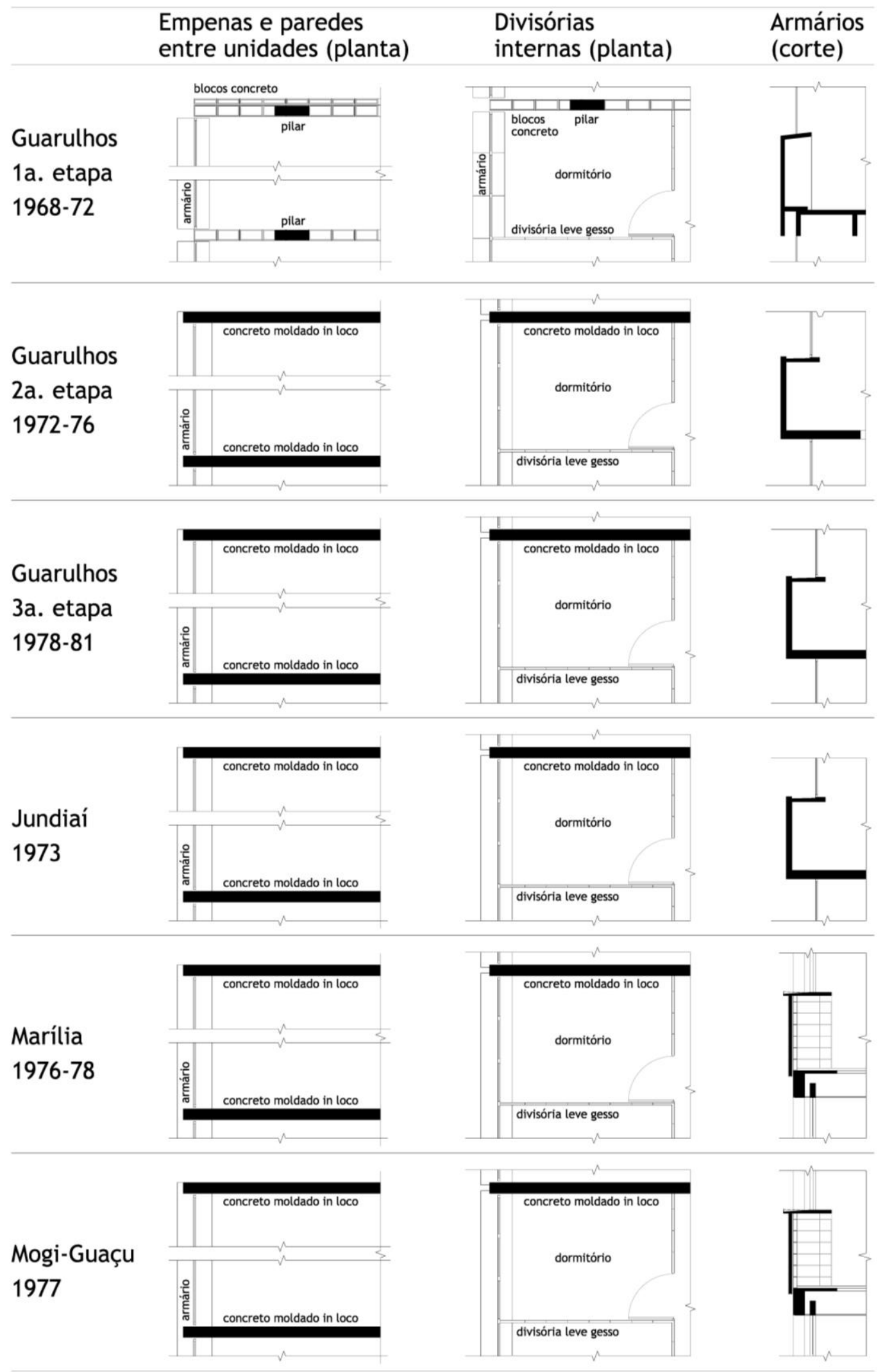


A partir de Guarulhos, como projeto seminal, foram implantados conjuntos habitacionais derivados em outras cidades do estado de São Paulo, sendo construídos os conjuntos da Cecap em Jundiaí, Marília e Mogi-Guaçu. Projetados e construídos simultaneamente às obras de Guarulhos, contemplaram o desenvolvimento, a reavaliação e as adaptações daquelas soluções projetuais e construtivas. Enquanto o projeto de Jundiaí é mais conhecido e registrado em diversas publicações, os dois menores são pouco conhecidos. Há a menção breve sobre o conjunto de Marília em dissertações, e não foi encontrada nenhuma publicação que tratasse do conjunto de Mogi-Guaçu. Assim, este trabalho contribui para o registro e a disseminação dos "pequenos" conjuntos Cecap".

Considerando o conjunto Cecap Zezinho Magalhães Prado um modelo, em que medida as reproduções aconteceram e quais as mudanças em relação ao modelo original? Os "pequenos" conjuntos Cecap possuem adaptações que não os fazem ser uma mera cópia? O exame comparativo dos conjuntos revela que os conjuntos derivados não são apenas uma reprodução literal, mas soluções híbridas, que possuem adaptações aos novos contextos e portes dos projetos.

De fato, em termos de conformação e organização, os "pequenos" conjuntos Cecap são derivados não de Guarulhos, mas diretamente da solução de Jundiaí, tendo como principais características similares o arranjo dos blocos e a utilização de rampas. Com relação às soluções construtivas, enquanto Jundiaí incorporava os aprimoramentos técnicos como uso de formas metálicas, simplificando lajes e fachadas, em Marília e MogiGuaçu o sistema estrutural e a técnica construtiva retomam a primeira fase de Guarulhos. A proposta da unidade habitacional (apartamento tipo) manteve-se praticamente inalterada em todos os conjuntos analisados.

O projeto original pode ser considerado, então, um modelo. Do ponto de vista conceitual, Quatremère de Quincy (1832) foi quem primeiro diferenciou "tipo" de "modelo": enquanto o modelo é um objeto que deve repetir-se tal qual foi idealizado, o tipo, ao contrário, é um objeto com base no qual podem ser concebidas obras que não se pareçam; enquanto o tipo é algo vago e não pode ser meramente copiado, o modelo é preciso e reprodutível; tipo seria uma ideia genérica, uma essência subjacente ao aspecto físico, algo como o espírito do edifício, e o modelo aquilo que pode ser repetido com rigor, como um carimbo.
(ARGAN, $1963^{25}$ apud NESBITT, 2006; ARÍS, 1993; ROSSI, 1995; MAHFUZ, 1995). O modelo é uma forma familiar, testada e aceita, e tal escolha implica no "[...] reconhecimento de que uma certa obra de arte é a melhor solução para um dado problema e por isso deve ser imitada [...]" (ARGAN, $1963^{26}$ apud MAHFUZ, 1995). Ao tratar do método mimético de projeto, Mahfuz (1995) afirma que o existente não é copiado fielmente, mas interpretado e adaptado, pois, ao ser transposto no tempo e no espaço, “[...] sempre há diferenças contextuais, e só este fato já impossibilita a cópia literal [...]” (p. 58). É o caso dos "pequenos" Cecap.

Por que Jundiaí se tornou o novo modelo para os "pequenos" conjuntos Cecap? A solução das rampas unindo os blocos em meios níveis além de ser uma resposta natural à declividade do terreno simplificou ainda mais o processo de construção: na medida em que as passarelas e escadas teriam que ser moldadas in loco, as rampas são muito mais simples e permitem facilmente o reaproveitamento das formas, mesmo que de madeira. Ademais, apesar do percurso maior a ser percorrido pelos moradores e da declividade relativamente acentuada, há indícios em depoimentos de moradores de que a solução é muito bem aceita.

Além disso, questões de fundo permanecerão: se a execução da obra se deu de modo convencional sem a implementação da pré-fabricação, por que os conjuntos posteriores ainda mantiveram as mesmas características básicas? Por que a Cecap adotou os blocos de apartamentos de Guarulhos como modelos para implantação em outras cidades? Para Cunha (2009), isso é uma demonstração do esforço ou da radicalização de Artigas na direção da industrialização da construção, uma "luta" por um desenho tecnicamente avançado, combatendo o atraso.

De fato, não há respostas definitivas, mas de modo pragmático é possível conjecturar. Primeiro, do ponto de vista da qualidade espacial: a reprodução do modelo deu-se com relação apenas aos blocos de apartamentos. A qualidade funcional dos apartamentos, percebida logo no início da ocupação da primeira fase de Guarulhos, credenciou o modelo como uma boa solução. Dentro da contingência de $64 \mathrm{~m}^{2}$, a unidade tinha a possibilidade de ter o terceiro dormitório, possuía iluminação adequada e ventilação cruzada; a solução de cobertura, com laje "afogada", conferia

\footnotetext{
${ }^{25}$ ARGAN, G. C. On the Typology of Architecture. Architectural Design, Londres, n. 33, p. 564-65, dez. 1963.

${ }^{26}$ ARGAN, G. C. On the Typology of Architecture. Architectural Design, Londres, n. 33, p. 564-65, dez. 1963.
} 
isolamento térmico ${ }^{27}$; os espaços pequenos eram otimizados com a previsão dos armários nos peitoris, cujo pequeno balanço também protegia as aberturas. Ou seja, um bom modelo a ser reproduzido.

Segundo, houve muito esforço empenhado no sentido de racionalizar o projeto e os processos construtivos, a fim de produzir edifícios de fato econômicos, apesar de não pré-fabricados. Nos depoimentos dos arquitetos da equipe, é recorrente a menção às espessuras médias de concreto de 9 $\mathrm{cm}$, o que reduziu consideravelmente o peso e o custo com material.

Terceiro, é possível deduzir que os pilotis, ao liberar o térreo, criaram um espaço livre, aberto, permeável - mesmo que passasse a ser usado como estacionamento - inexistente em empreendimentos análogos. O ganho na qualidade espacial era muito grande e foi possível economicamente graças às soluções técnicas encontradas.

Por último, deve ser considerado o processo de projeto de habitações sociais em companhias públicas de habitação: por mais capacitadas que fossem as equipes, quais as chances de propor e desenvolver soluções superiores àquelas exaustivamente discutidas por grandes arquitetos e testadas naquela escala? Seria natural, então, o reconhecimento do conjunto Cecap Guarulhos como uma boa solução, ainda que com ajustes e adaptações, um bom modelo a ser reproduzido.

\section{Referências}

ACRÓPOLE. São Paulo, v. 31, n. 372, abr. 1970.

ARANTES, P. F. Arquitetura Nova: Sérgio Ferro, Flávio Império e Rodrigo Lefèvre, de Artigas aos mutirões. São Paulo: Editora 34, 2002.

ARÍS, C. M. Las Variaciones de la Identidade: ensayo sobre el tipo em arquitectura. Barcelona: Ediciones del Serbal, 1993.

BLACHÉRE, G. Tecnologías de la consTrucción Industrializada. Barcelona: Gustavo Gili, 1978.

BRUNA, P. J. V. Arquitetura, Industrialização e Desenvolvimento. São Paulo: Editora Perspectiva, 1976.

CAMARGO, M. J. A Arquitetura de Vilanova Artigas e a Construção da Cidade Moderna. Jornal da Unicamp, Campinas, 3 out. 2014. Resenha, p. 8.
CERÁVOLO, F. A Pré-Fabricação em Concreto Armado Aplicada a Conjuntos Habitacionais no BRASIL: o caso do conjunto habitacional Zezinho Magalhães Prado. São Carlos, 2007. Dissertação (Mestrado em Arquitetura e Urbanismo) - Escola de Engenahria, Universidade de São Paulo, São Carlos, 2007.

CUNHA, G. R. Uma Análise da Produção de Vilanova Artigas Entre os anOs de 1967 a 1976. São Carlos, 2009. Dissertação (Mestrado em Arquitetura e Urbanismo) - Escola de Engenahria, Universidade de São Paulo, São Carlos, 2009.

FERRAZ, M. C. (Coord.). Vilanova Artigas. São Paulo: Instituto Lina Bo e P. M. Bardi, 1997.

FICHER, S. Subsídios para um estudo do conjunto habitacional Zezinho Magalhães Prado. 1972. Monografia de conclusão de curso (Graduação em Arquitetura). Faculdade de Arquitetura e Urbanismo, Universidade de São Paulo, São Paulo, 1972.

FRENCH, H. Os Mais Importantes Conjuntos Habitacionais do Século XX: plantas, cortes e elevações. Porto Alegre: Bookman, 2009.

GROPIUS, W. Bauhaus: novarquitetura. São Paulo: Perspectiva, 1977.

GUADANHIM, S. J. Habitação Coletiva Contemporânea. Londrina: Humberto Yamaki, 2014.

KAMITA, J. M. Vilanova Artigas. São Paulo: Cosac e Naify, 2000.

KATINSKY, J. R. Acervo João Batista Vilanova Artigas. Pós, São Paulo, n. 18, p. 196-211, dez. 2005.

\section{MAHFUZ, E. C. Ensaio Sobre a Razão}

Compositiva: uma investigação sobre a natureza das revelações entre as partes e o todo na composição arquitetônica. Viçosa: UFV, Impr. Univ.; Belo horizonte: AP Cultural, 1995.

MEDEIROS, L. D. Análise da Eficiência Térmica em Conjunto Habitacional: o estudo de caso Zezinho Magalhães Prado - CECAP. São Paulo. 2014. Dissertação (Mestrado em Arquitetura e Urbanismo) - Escola de Engenharia, Universidade Presbiteriana Mackenzie, São Paulo, 2014.

MEDRANO, L.; RECAMÁN, L. Vilanova

Artigas: habitação e cidade na modernização brasileira. Campinas: Editora da Unicamp, 2013.

${ }^{27}$ Uma análise da eficiência térmica do Conjunto Zezinho Magalhães foi realizada por Medeiros (2014). 
MONTENEGRO FILHO, R. A. de L. PréFabricação e a Obra de Eduardo Kneese de Mello. São Paulo, 2007. Dissertação (Mestrado em Arquitetura e Urbanismo) - Faculdade de Arquitetura e Urbanismo, Univesidade de São Paulo, São Paulo, 2007.

NESBITT, K. Uma Nova Agenda Para a Arquitetura: antologia teórica (1965-1995). São Paulo: Cosac Naify, 2006.

PISANI, D. Paulo Mendes da Rocha: obra completa. São Paulo: Gustavo Gili, 2013.

QUATREMÈRE DE QUINCY, A. C. Dictionaire Historique d'Architecture. Paris: Librairie d'Adrien Le Clerc, 1832.

REVISTA DESENHO. São Paulo, v. 4, maio 1972.

ROSSI, A. A arquitetura da Cidade. São Paulo: Martins Fontes, 1995.

SABBATINI, F. H. Desenvolvimento de Métodos, Processos e Sistemas Construtivos: formulação e aplicação de uma metodologia. São Paulo, 1989. Tese (Doutorado em Engenharia Civil) - Escola Politécnica, Universidade de São Paulo, São Paulo, 1989.

SEGAWA, H. Arquiteturas no Brasil: 19001990. 2. ed. São Paulo: EDUSP, 2002.

YIN, R. K. Estudo de caso: planejamento e métodos. Porto Alegre: Bookman, 2010.
ZANDONADE, P. Conjuntos Habitacionais no Tecido Urbano da Área Metropolitana de São Paulo: o caso da Região Leste (1930/1986). São Paulo, 2005. 161 fls. Dissertação (Mestrado em Arquitetura e Urbanismo) - Escola de Engenharia, Universidade de São Paulo, São Paulo. 2005.

ZEIN, R. V. A Arquitetura da Escola Paulista Brutalista 1953-1973. Porto Alegre, 2005. Tese (Doutorado em Arquitetura) - Escola de Engenharia, Universidade Federal do Rio Grande do Sul, Porto Alegre. 2005.

\section{Agradecimentos}

À Hana Beatriz El Ghoz, pelo auxílio na pesquisa; à Biblioteca da FAUUSP, pela disponibilização do material do acervo Vilanova Artigas; à Ariane Boa Sorte Ogasavara, pela disposição em colaborar na busca pelas documentações nos acervos da FAUUSP; à Wilza Aurora Matos Teixeira, bibliotecária da Câmara Municipal de Marília, pela atenção, imagens e informações cedidas sobre o conjunto Cecap Marília; aos síndicos dos conjuntos Cecap visitados, pela autorização de entrada nos conjuntos; aos moradores dos conjuntos visitados que permitiram o acesso aos seus apartamentos, o que possibilitou o conhecimento das unidades; e àqueles que gentilmente concederam depoimentos aos autores.

Wilton Flávio Camoleze Augusto

Curso de Arquitetura e Urbanismo | Universidade de Marília | Avenida Higyno Muzzy Filho, 1001, Campus Universitário | Marília - SP . Brasil | CEP 17525-902 | Tel.: (14) 2105-4044 | E-mail: wfcau@hotmail.com

Sidnei Junior Guadanhim

Departamento de Arquitetura e Urbanismo, Centro de Tecnologia e Urbanismo | Universidade Estadual de Londrina | Rodovia Celso Garcia Cid, PR 445, km 380, Campus Universitário | Caixa Postal 6001 | Londrina - PR - Brasil | CEP 86055-900 | Tel.: (43) 33714535 |

E-mail: sjg@uel.br

Revista Ambiente Construído

Associação Nacional de Tecnologia do Ambiente Construído

Av. Osvaldo Aranha, $99-3^{\circ}$ andar, Centro

Porto Alegre - RS - Brasil

CEP $90035-190$

Telefone: +55 (51) 3308-4084

Fax: +55 (51) 3308-4054

www.seer.ufrgs.br/ambienteconstruido

E-mail: ambienteconstruido@ufrgs.br 